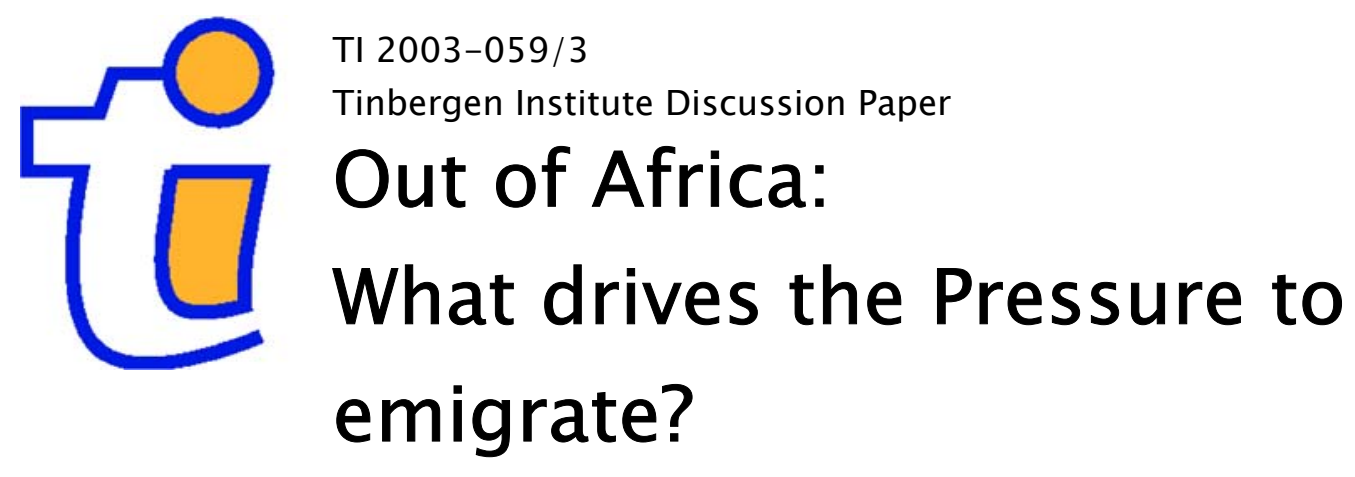

Hendrik P. van Dalen 1,2,3

George Groenewold ${ }^{1}$

Jeannette J. Schoorll

${ }^{1}$ Netherlands Interdisciplinary Demographic Institute (NIDI), The Hague,

2 Faculty of Economics, Erasmus University Rotterdam,

3 Tinbergen Institute. 


\section{Tinbergen Institute}

The Tinbergen Institute is the institute for economic research of the Erasmus Universiteit Rotterdam, Universiteit van Amsterdam, and Vrije Universiteit Amsterdam.

Tinbergen Institute Amsterdam

Roetersstraat 31

1018 WB Amsterdam

The Netherlands

Tel.: $\quad+31(0) 205513500$

Fax: $\quad+31(0) 205513555$

Tinbergen Institute Rotterdam

Burg. Oudlaan 50

3062 PA Rotterdam

The Netherlands

Tel.: $\quad+31(0) 104088900$

Fax: $\quad+31(0) 104089031$

Please send questions and/or remarks of nonscientific nature to driessen@tinbergen.nl.

Most TI discussion papers can be downloaded at http://www.tinbergen.nl. 


\title{
Out of Africa: What Drives the Pressure to Emigrate? ${ }^{1}$
}

\author{
Hendrik P. van Dalen ${ }^{*}$, George Groenewold* and Jeannette J. Schoorl
}

* Netherlands Interdisciplinary Demographic Institute (NIDI)

P.O. Box 11650

NL - 2502 AR The Hague

The Netherlands

$=$ Erasmus University Rotterdam

Department of Economics and Tinbergen Institute

P.O. Box 1738

NL-3000 DR Rotterdam

The Netherlands

April 15, 2004

\begin{abstract}
.
Who intends to leave Africa and what drives the pressure to emigrate? For four African countries (Ghana, Senegal, Morocco and Egypt) we evaluate the strength of push and pull factors in stating emigration intentions 'out of Africa'. In general, one can say that the typical potential migrant is young, male, optimistic about attaining a higher living standard and finding a job and having relatively modern values compared to those who intend to stay. Classical push factors like unemployment and poverty are present in most countries. The most notable finding is extent with which the optimism surrounding the net benefits of migration drives emigration intentions out of Africa, especially in Ghana and Senegal. Besides this general observation, each and every country tells a different story. Signs of positive self-selection with respect to the level of education of potential migrants are clearly present in Ghana and Egypt, especially among women. However, negative self-selection applies to the case of Moroccan men. The network effects of potential migrants turn out to be of some importance in Ghana and Egypt. However, in Senegal and Morocco such ties are apparently not as important as one might expect from studies of actual migration behaviour. In Morocco the prevailing migration culture offers a plausible explanation and in Senegal the high frequency of migration in regions with an established migration history offers some of the services that network ties might offer.
\end{abstract}

JEL classification: F22, O52, P2

Key words: Migration, intentions, Africa, selection, networks

* Comments by Kène Henkens, Beth Fussell and two anonymous referees are gratefully acknowledged. Earlier drafts of the paper were presented at the 2003 annual meeting of the European Association for Population Studies in Warsaw and the 2004 annual meeting of the Population Association of America in Boston. Financial support by the Dutch Ministry of Foreign Affairs is gratefully acknowledged.

\footnotetext{
${ }^{1}$ All correspondence to: Hendrik P. van Dalen, Netherlands Interdisciplinary Demographic Institute (NIDI), P.O. Box 11650, NL - 2502 AR The Hague, The Netherlands, Tel: +3170 - 3565237, Fax: +3170 - 3647187, email: dalen@nidi.nl
} 


\section{Introduction}

Africa is a continent that does not raise high hopes among development experts. Gallup et al. (1998) predict that much of the population increase in the next thirty years is likely to take place in geographically disadvantaged regions in the world, notably Africa. High fertility rates together with low life expectancies tend to be associated with lower rates of saving and investment and therefore slower economic growth (cf. Bloom and Sachs, 1998). Hatton and Williamson $(2002,2003 \mathrm{a})$ arrive at the conclusion that the emigration pressure in Africa for the next twenty years will be increasing, as the population age structure will continue to show increases in numbers of young adults, who might try their luck elsewhere. The lack of any economic growth prospects in Africa will only reinforce emigration pressure. The present state of Africa has not always been so dismal. In the sixties and the start of the seventies Africa's future looked bright, but during the seventies economic and political matters in Africa deteriorated (Collier and Gunning, 1999). Since 1980, aggregate per capita GDP in Sub-Saharan Africa has declined at almost one percent per year and today sub-Saharan Africa is the lowest income region in the world. To many African citizens emigration 'out of Africa' seems to be the only way in their mind to improve their standard of living. ${ }^{1}$

The above mentioned analyses and 'guesstimates' are primarily based on aggregate statistics and not much is known about the microeconomic causes and incentives that trigger migration in Africa, although not much is needed to imagine that the pressure to emigrate is real. This lack of knowledge is troubling as governments of destination countries are increasingly thinking about how to keep migrants out, without turning to the actual source of the emigration pressure. Migration and development policies might have a better chance of succeeding if both sides of the migration story - the circumstances in both the countries of origin and of destination - are taken into account (cf. Rotte et al., 1997, and Vogler and Rotte, 2000). In that respect one can understand why Borjas (1994: 1668) in the recent past made the claim that "an assessment of the economic impact of immigration requires an understanding of the factors that motivate persons in the source countries to emigrate.” In the present paper we will examine precisely this point. We will concentrate on the issue of who intends to leave and who stays behind in a number of African countries (Ghana, Morocco, Senegal and Egypt). It is a question that goes to the heart of the debate about the causes and consequences of the so-called 'brain drain' or more generally the size and structure of the South-North migration flow. For both the destination and the source country it matters (1) how high the 
migration flow is and (2) who leaves, as emigration will affect the age and sex structure of the population at large and the educational and skill composition of the labour force.

By employing international migration surveys for these countries we are able to show how high the pressure to emigrate is and what kind of forces are at work when it comes down to forming emigration intentions. As migration is a volatile event and hard to predict, understanding intentions to emigrate from developing countries can be of some importance in putting the previously mentioned migration predictions in perspective. Besides using migration intentions as predictors of future emigration flows, we also think that intention data could alternatively be used as indicators of the state of a country as people are in fact giving a vote of confidence in the future of their home country vis-à-vis other countries.

We are, of course, not the first to examine international migration intentions (cf. Burda et al., 1998, Faini, 1999, Papapanagos and Sanfey, 2001, Drinkwater, 2002, Liebig and SousaPoza, 2004), but our research adds two novel elements that can be added to the empirical literature of intentions. First of all, we bring together micro-data about emigration intentions for a number of African countries (Ghana, Senegal, Morocco and Egypt), countries that differ quite distinctly by geographic position, state of economic development, and cultural setting. The conjectures and the aggregate predictions that are often made about the African continent are not based on micro-evidence, and as such this paper is - as far as we know - a first attempt at filling this void for Africa.

Second, in modelling emigration intentions we will focus on structural characteristics that trigger self-selection or 'push' potential migrants and variables that 'pull' them towards the country of destination. Of course, modelling migration in such a manner is perhaps standard practice in estimating actual migration. However, within the economics literature that uses emigration intentions the simultaneous inclusion of push and pull factors is an exception. For instance, in the work Papapanagos and Sanfey (2001), Liebig and Sousa-Poza (2004) and Drinkwater (2002) expectations play no role at all and they concentrate solely on structural characteristics of potential emigrants.

Of course, the use of expectations is more or less standard practice in socialpsychological work that draws on Ajzen (1988)'s theory of planned behaviour. In such studies migration is seen as a decision making process in which the future attainment of valued goals in the home community (the stay decision) is evaluated against the attainment of those goals in alternative locations (the move decision). Notably the work by De Jong (see for instance, De Jong, 2000) should be mentioned at this point as he has used expectations about a variety of factors. For instance, De Jong (2000) shows for internal migration in Thailand that 
expectations concerning a variety of dimensions about the destination (standard of living, comfort, social support network) along with family norms about migration are major predictors of the intention to move, in particular for women. However, his work primarily concentrates on internal migration in developing countries and offers no comparison for our work, which focuses on expectations in the perspective of international migration.

Furthermore, in estimating intentions we have purged the effects that structural individual characteristics might have on the expectations about the net benefits of migration and constructed a variable that approximates the individual-specific optimism surrounding these benefits. As will become clear individual optimism about the benefits of migration are the prime driving force behind emigration intentions. Whether optimism is identical to overconfidence or overshooting is unclear at this point as intentions are at the focus of attention and not actual behaviour. But the fact that great expectations have such a strong impact on intentions point at a potentially simple explanation of why it is so hard to redress South-North migration flows.

After this introduction we will first discuss briefly the theory behind emigration intentions in section 2 and the role expectations play in this regard. Subsequently we will turn to the data in section 3, where the background of the survey is presented together with some salient stylized facts about the four African countries. In section 4 we expand briefly on the method of estimation and the model to be estimated. In section 5 we present the estimation results for the four African countries. In section 6 we test for the robustness of these results by examining intentions of both men and women. We conclude our paper with a summary of the main conclusions in section 7.

\section{Theory of Emigration Intentions}

Basic economic theory of migration ${ }^{2}$ stresses that differences in (expected) net returns across countries as the prime driving force behind emigration movements. A migrant with skill level $S$ who moves from a poor country (denoted by a $P$ ) to a rich country $(R)$ compares the two income level he ${ }^{3}$ might receive. In the poor country he knows what he receives and will probably receive over his remaining lifetime, viz. $E\left[W_{P}(S)\right]$ and he expects that the wage for a worker with comparable skill level $S$ in the rich country receives $E\left[W_{R}(S)\right]$ where clearly $E\left[W_{R}(S)\right]>E\left[W_{P}(S)\right]$. Income flows are discounted in order to compare this future income flow with his present wage. However, in deciding to migrate the potential migrant subtracts the costs $C(S)$ tied to moving abroad from the expected wage. The costs can be split up into explicit, once-and-for-all migration costs (transport, legal papers, etc.) and indirect, but 
nonetheless important costs of migration, such as the psychic costs of leaving family and country, net social security benefits or taxes, adjustment costs in the country of destination, etc. Of course, the costs can also be tied to immigration policies that the potential migrant encounters. Point systems used by countries like the Australia, New Zealand and Canada, where age, language fluency and education are important selection criteria for gaining entrance in these countries pose considerable costs as potential migrants will have to invest in, e.g., education to be able to earn the threshold number of points for obtaining a visa. Taking all relevant variables together, the individual living in the poor country will migrate as long as:

$$
E\left[W_{R}(S)-C(S)\right]>E\left[W_{P}(S)\right]
$$

In making emigration decisions there are processes at work that seem to lead to self-selection among migrants as the net benefits of migration are not the same for everyone (see Chiswick, 1999). Furthermore, in predicting who will emigrate it matters what the structure of information asymmetry looks like across migrants and potential employers in the country of destination. This element is at the focus of attention in the theory of adverse selection. This theory basically boils down to the proposition that in the presence of asymmetric information and the absence of signalling or screening by market participants only the 'bad quality' products are traded in equilibrium. This theorem can easily be applied to the questions of migration, as Katz and Stark (1987) show, in which case the proposition reads as follows: in the absence of signalling or screening, only the low skilled or low educated are the ones who emigrate. Of course, signals such as education and screening by employers do play a role in obtaining employment abroad, thereby leading to more complex migration flows in which, e.g., only the high skilled and low skilled migrate (Katz and Stark, 1987: 721-723). The theory of adverse selection focuses on the information asymmetry between employers and employees.

A shortcoming of the analysis by Katz and Stark (1987) is that it does not deal explicitly with the formation of expectations which migrants have about the prospective wage or income level abroad. In making decisions the potential migrant has to form expectations and our hunch is that part of the migration flows 'out of Africa' can be explained by paying attention to the formation of expectations. Expectations open the possibility of overshooting or undershooting in migration. For instance, the existence of a migration culture in which everyone intends to emigrate or plans to emigrate can be simply the result of expectations that 
are out of touch with the actual circumstances abroad. As a consequence of, for instance, an overoptimistic population, an inefficient number of migrants will leave the country. Take a look at Figure 1 where net wage curves are given under conditions of complete certainty in such a manner that migrants of skill level $S$ and higher will leave the country as at that point $W_{R}-C>W_{P}$.

\section{HERE FIGURE 1}

However, if expectations are such that across the entire population in the source country wage expectations are shifted upwards towards $W_{R}{ }_{R}$, the potential migrants can under those circumstances be found in the pool of skill level $S^{\prime}$ and higher (where $S^{\prime}<S$ ). In other words, the pool of migrants leaving the country is of undereducated or underskilled and within this simple framework the group $\left(S-S^{\prime}\right)$ will be disappointed as their real wage in the country of destination will fall below their expected wage. ${ }^{4}$ One can even think of the situation in which wage expectations are so high that the entire population, no matter what skill level, will be eager to move abroad. Of course, optimism is bound to differ across individuals and the assumptions under which a genuine migration culture exists are quite stringent. Much depends in questions of self-selection on the height and slopes of the relevant net wage curves. Unfortunately one can therefore not predict on a priori grounds who will migrate and who will stay. Empirical evidence has to shed light on the characteristics of potential migrants.

\section{Intention theory}

In this study we will not use revealed emigration behaviour but we will focus on stated emigration intentions. Using intentions as an approximation of future emigration decisions is a reasonable research strategy as long as one is aware of the pros and cons of using such stated preferences. A clear advantage in the use of migration intention data is that it allows one to test self-selection theories without having to deal with sample selection problems that are tied to host-country data. Quite a number of studies that test for self-selection of migrants rely on host-country data and as Liebig and Sousa-Poza (2004: 126) point out such an approach can become problematic as specific host-country characteristics such as migration policy, historical links and geographical proximity are bound to bias immigration to these countries.

Most researchers who use intention data refer to the so-called 'theory of reasoned action' of social psychologists (see Fishbein and Ajzen, 1975; and Ajzen, 1985, 1988) as their 
basic frame of reference. This theory revolves around the hypothesis that a person's intention to undertake a certain action (e.g., investment, labour supply, giving up smoking, etc.) is a function of, amongst other factors, the beliefs about the consequences of a certain action. For the case of emigration this implies that the person makes a mental map of the costs and benefits that are tied to the decision to emigrate. The decision to migrate becomes a real option in the minds of non-migrants when the present value of benefits exceeds the present value of costs. Intention theory is in that respect not that much different from economic theory, albeit that the social-psychological factors that impinge on decision making is far larger and more difficult to explicate.

Using intentions warrants a number of comments as the analysis of intentions is, however, riddled with difficulties and pitfalls that are hard to reconcile if one wants to use intentions as predictors of future behaviour. The framing of questions - it matters whether the question is open ended or whether it is a 'forced choice' question - and the fact that the information available at the time when people form their intention and the information they possess when the actual steps are taken may differ substantially are good reasons to interpret intention data with care. Unfortunately, the available data do not allow us to test the relationship between intended and actual decisions. Still, as Manski (1990) makes clear in a short review on the subject, intention data do convey information about subsequent behaviour and at most one can estimate the bounds so as to test the 'best case' hypothesis, i.e. the respondent has rational expectations and their responses to questions are best predictions of their future behaviour. Furthermore, social psychologists are fairly confident about the applicability of the relation between intentions and actions. The so-called 'theory of reasoned action' (Ajzen, 1985: 15) “permits highly accurate predictions in a wide variety of behavioural domains." However, one does have to be careful in making this claim as not every individual decision problem fits the problems social psychologists refer to. The tacit assumption behind the theory of 'reasoned action' is that, barring unforeseen events, people are expected to act in accordance with their intentions and in a rational manner. Another assumption is that individuals perceive to be in control of what lies between their stated 'intention to move' and the actual move abroad (i.e. their so-called 'self-efficacy'). In other words, whether they believe they can "make things happen".

Of course, intentions can change over time, not only because of preference drift but primarily because circumstances change and so will expectations. The accuracy of predictions based on intentions will probably be an inverse function of the time interval between measurement of intention and the observation of the intended behaviour. This is especially 
relevant in the case of migration. For instance, voting for a specific politician or watching a specific television program are decisions that are easily performed and cover a short horizon, whereas the volitional control may be extremely low in the case of emigration.

Most studies on migration intentions (De Jong et al., 1996; Sandu and De Jong, 1996; De Jong, 2000; Fawcett, 1986; Hughes and McCormick, 1985, Gordon and Molho, 1995; Lu, 1999; Yang, 2000) focus on internal or regional migration as such migrants are relatively easily traced for a follow-up survey to check on the realisation of these intentions. The results of these studies are encouraging. De Jong (2000) shows for the case of Thailand how the intention to migrate can be a powerful predictor of the actual decision to emigrate permanently. However, little is known about the extent to which intentions to move abroad lead to actual migration, but one can imagine that the gap between intention and action will be large, at least larger than for internal migration data. Prospective migrants are not only in need of resources to finance their move abroad but they also need to surpass formal barriers as obtaining a visa, residence permits, and/or work permits; legal papers which are increasingly hard to obtain. Gardner et al. (1986: 70) present some evidence that potential international migrants in the Philippines who did not realise their intentions were mainly thwarted by legal migration hurdles. Intentions to migrate internationally seem to reflect therefore the willingness to act upon opportunities, in the realisation that such opportunities may be slow to arise and quickly fade away if they arise.

\section{Modelling intentions}

Most of the international migration intention studies take as a starting point to examine the structural characteristics (age, sex, marital status, education, profession) of potential movers and stayers. To compare results across studies verges on the impossible as each and every study takes a different tack, employs different methods and uses different theories to shed light on migration intentions. Furthermore, it is unfortunate that research on African data is lacking which would give us to possibility to compare results.

Still, an overall conclusion about intentions to emigrate is that these intentions are significantly higher among young (and single) men. Being unemployed or being educated provides also a stimulus to consider a move abroad more seriously, although these results do not show up for each and every country. For instance, Papapanagos and Sanfey (2001) use the Central and Eastern Europe Eurobarometer of 1992 to examine emigration intentions in Albania in particular and - as to be expected with countries in turmoil - the willingness to 
move abroad was extremely high, especially among men: more than 70 percent express an intention to move to Western Europe, compared with just over 50 percent of the women.

To compare these intentions with some more recent research the papers of Drinkwater (2002) and Liebig and Sousa-Poza (2004) may be instructive. They used the 1995

International Social Survey Programme (ISSP) in order to shed some light on the willingness to move of residents of Western developed countries and those of Central and Eastern European Countries (CEEC) and they come up with a relatively surprising result that the willingness the move abroad is lower in the CEECs than it is in the EU. It is surprising because it stands in marked contrast with the figures presented in Papapanagos and Sanfey (2001) of the early 1990s and because the scheduled enlargement of the EU is thought to be accompanied by large scale migration flows (see, e.g., Blanchard, 2002). Furthermore, it should be noted that the EU population is not particularly known for being highly mobile (see, e.g., Faini, 1999). With hindsight it may, however, be quite easily explained why these researchers find such diverging results: the question posed in the ISSP-questionnaire captures the 'willingness to move' ("Would you be willing to move to another country to improve your work or living conditions?"), whereas Papapanagos and Sanfey (2001) ask for the 'probability of moving' ("How likely is it that you will move to Western Europe?”). It goes without saying that willingness to move is a concept where the commitment is rather low, contrary to the 'intention to move' which forces respondents to make some (weak) form of commitment.

\section{... and expectations}

In our view, expectations about the costs and benefits tied to moving abroad are a crucial ingredient in understanding the formation of emigration intentions, besides other structural characteristics. O'Connell (1997) shows that predictions of migration under conditions of uncertainty are quite sensitive to the structure of information and the type of uncertainty that is assumed. In general one can distinguish between two types of uncertainty that matter in decision making for a potential migrant: uncertainty referring to (1) current conditions in the destination country that may not be observable; and (2) the future evolution of conditions in both the source and the destination country. The first type of uncertainty may trigger so-called speculative migration, i.e. migrants will just "try their luck" in foreign labour markets. The other type of uncertainty about the future net benefits may discourage migration as migrants may just "wait and see", i.e. they will wait until some of the uncertainty has resolved. O'Connell's theory offers a plausible theory why not everyone migrates in the face of diverging wage developments. Empirical tests of this theory are scarce, although the work by 
Burda et al. (1998) can be seen as the exception to the rule. They study East-West German migration intentions and focus on the opportunity costs of migrating today instead of tomorrow or the distant future. The theory of the option value of waiting is that individuals do not immediately move in response to observed wage differentials because of uncertainty about future wage levels. It may very well be optimal to 'wait and see' and postpone migration until some of the uncertainty at home and at the destination is resolved. Burda et al. (1998) show how the effect of income on migration intentions takes a U-shaped form, which they interpret as an effect that is compatible with the option value theory, but which could also be accounted for by borrowing constraints in financing migration. They acknowledge the exploratory character of their work and the need for more information in estimation in order to identify which forces are operative and for which individuals. Our work can be seen as complementary to this type of work as we explicitly include expectations about the net benefits of migration, although a replication of their work is impossible as income in the surveyed countries is not registered as a continuous variable and in Africa income is a far more diffuse concept than it is in highly developed countries. ${ }^{5}$

\section{Data}

\subsection{Migration survey}

To assess motives, expectations and intentions to emigrate we have used special purpose migration surveys. In the years 1997/1998 international migration surveys were implemented in a number of developing countries to explore the forces that push potential emigrants out of a country or that pull the potential emigrant towards specific countries, in particular countries in the European Union. ${ }^{6}$ For the purpose of the project, primary data have been collected on individuals, their households and their communities in a number of countries, focussing on South-North flows to the European Union. Co-ordinated by NIDI (Netherlands

Interdisciplinary Demographic Institute), seven research teams located in Mediterranean and West-African countries participated in the project: predominantly migrant-sending countries Turkey, Morocco, Egypt, Senegal, and Ghana, and the newly immigrant-receiving countries Italy and Spain. In the present article we will only focus on the four sending countries in the African continent:

- Morocco. This is a country with a long tradition of emigration towards Europe. Since the 1960s emigration of Moroccan workers has taken place, heading mainly for France which recruited several tens of thousands of unskilled workers over a period of 15 years. Other 
European countries also sought to recruit Moroccans, such as Belgium and the Netherlands and to a lesser extent Germany. For the Moroccan government this emigration fitted with their strategy of coping with high unemployment and benefiting from the migrants' remittances. After the recruitment of so-called 'guest workers' in the early and mid-1970s ceased, migration flows continued through family reunification and family formation (by marriage). The attachment of Moroccan emigrants to their country has generally not diminished and the strength of family ties also explains the emergence of migration networks which have made it possible to maintain migration to EU countries, in spite of the stricter immigration controls instituted by host countries to control these flows. The worries of host country (European) governments about the emigration of Moroccans seem to be justified as their capabilities and values do not seem to be in tune with the Western world: illiteracy rates are high, especially among women and the official language is Arabic. Practically all Moroccan citizens belong to either the Arab or the Berber ethnic group; and almost all are Muslims.

- Egypt. For Egypt emigration has always been much more important than immigration. At the time of the survey it was estimated that about two million Egyptians lived abroad. Economic motives are dominant in triggering migration. From the mid-1960s to the mid1970s, mostly unskilled rural workers left Egypt. In more recent times, when Saudi Arabia became their favourite destination, the proportion of skilled migrants strongly increased. The educational level in Egypt remains low, especially for women. Illiteracy rates among women are still very high (61 percent in 19950 and tend to be concentrated in the poorer rural areas. Ethnic groups are predominantly Egyptians, Bedouins and Berbers. The vast majority of the population (94 percent) is Muslim, mostly Sunni. Arabic is the official language. The pressure to migrate is high in Egypt as living standards are quite low and the lure of the West and the OPEC-countries will keep the pressure going. The importance of remittances for the economy of Egypt has increased tremendously as it is by far the largest source of 'foreign' income.

- Senegal is a former colony of France and gained independence in 1960. Although few estimates of international migration flows to and from Senegal suggest a zero net migration balance it would seem more appropriate to assume that, given the low level of development and future prospects, Senegal faces a negative migration balance. The population of Senegal incorporates a diversity of ethnic groups. The largest of these include the Wolof (44 percent) and the Fulani and Tukulor (24 percent). French is the official language of Senegal, although Wolof is the most widely understood of the many 
African languages. The large majority of the population is Sunni Muslim (90 percent) and about 6 percent is Christian. The state of development of Senegal is even worse than that of Morocco and Egypt. Senegal is predominantly agricultural (70 percent of the labour force) and illiteracy rates are astoundingly high: three out of every four women aged 15 or older cannot read or write. Although education is compulsory in Senegal actual attendance rates are low and child labour is quite high (30 percent of all children aged 10-14).

- Ghana reveals a quite different story compared to the previous three countries: it used to attract many migrants from other African countries to work in cocoa production, but due to structural economic downturns it has now become a major emigration country. It is estimated that about ten percent of the Ghanaian population live abroad, especially in Nigeria. Ghana is also more ethnically diverse than, e.g., Moroccans, as there are six main ethnic groups of which the Akan (Ashanti and Fanti) are the most numerous group. Ghana seems to more in tune with modern values than the other observed countries as half of the population is Christian, English is the official language and the government is dedicated to strongly reducing the illiteracy rate.

To return to the set-up of the migration survey, in principle, all persons between the ages of 18 and 65 belonging to the household were eligible for an interview, including those who were presently living abroad. For those current migrants who were not present, information was gathered using proxy-respondents. The selection of the sending countries was based on the desire to capture typical migration flows in the region from the Southern and Eastern Mediterranean and Sub-Saharan Africa. Other selection criteria included the existence of a varied destination pattern of migrants, and different histories and colonial ties.

In order to facilitate interviewing, to study chain migration, and to reduce difficulties in finding international migrants in the countries of emigration (a problem not unlike finding needles in a haystack), the sample designs were targeted at specific regions. Using expert knowledge, in each country several regions were selected, depending on the level of development (relatively low versus relatively high) and the history of migration (longestablished versus fairly recent). Regions characterised by very limited international migration were not included. Within the regions chosen, multistage, stratified cluster samples of migrant and non-migrant households were taken. As a consequence of regional sampling, it should be noted that the results of the study do not reflect migration from the countries as a whole, but only from the regions selected. ${ }^{7}$ 


\subsection{Descriptive statistics and empirical puzzles}

We will first introduce some statistics on emigration intentions for the four African countries to get a feel for the importance of the phenomenon and the differences across countries. For the purpose of this paper, the key question in the survey was a question probing the intentions of respondents who never emigrated before: “Do you intend to migrate abroad?' The possible answers were "yes", "no" and "don't know". The respondents who had answered positively to this question were asked to indicate their intended departure period and to specify whether they had taken steps to obtain required documents (passports, visas, residence or work permits, etc.). In addition to these emigration intention questions, respondents were asked to indicate their main motivation for emigrating and their preferred country of destination. Table 1 summarises the main motives to migrate or to stay and intentions among non-migrants, i.e. persons with no international migration experience. Return migrants were excluded from our study.

\section{Here Table 1}

Evidently, there are clear differences in emigration intentions across countries. It is worth noting that the intention to emigrate is especially high among Ghanaians and Senegalese, whereas emigration intentions are low in Egypt. The main reason why can be traced to the stated motives to stay, among which family ties figure prominently. Finally, these figures could cover up the fact that the sex composition of the groups under consideration differ markedly. The intention to move abroad is significantly higher among men compared to women. More specifically, the intention to move is highest among men from Ghana and Senegal, where approximately 50 percent of the male respondents indicated that they intend to emigrate. Moroccan and Egyptian men are less set on migrating with 33 and 21 percent respectively saying they intend to emigrate. Women are less adamant in their intentions: only 4 percent of the (non-migrant) women from Morocco and Egypt state that they intend to emigrate whereas Ghanaian and Senegalese women are more eager on moving abroad: 37 percent and 26 percent respectively.

\section{Motivation: economic}

The next question that was raised in the questionnaire was: why do you intend to emigrate? The main answers unequivocally point to economic motives underlying the intention to emigrate in these countries. The reason for stating these motives are, of course, rooted in the 
present day economic circumstances and developments over time. However, it is quite hard to distinguish which economic factor dominates. Poverty could be a driving force as well as the fact that one expects that migration is a financially profitable move. Poverty is however an ambiguous explanatory factor as insufficient means may perhaps be a reason for emigration, but it could just as well be barrier to move as liquidity-constrained individuals can not afford the costs of emigration. The financial attractiveness of emigration, on the other hand, makes a plausible and unambiguous factor as the income gap between the industrialised world and the developing world only seems to have increased over the years. If we just take a look at the gap between GDP per capita in the countries under consideration and that of, for instance, the average US citizen (see Figure 2 below) then one can understand that the lure of 'going West' (USA) or North (Europe) is a real driving force for most respondents. The gap between Africa and the developed world (in the figure represented by the US) was already large fifty years ago, but in the mean time the gap has only widened, making migration a more and more likely step for these citizens. Macroeconomic studies of international migration by Hatton and Williamson (2003a) and Vogler and Rotte (2000) make clear that the income differential is an important driving force, especially for Africans.

\section{Here Figure 2}

The income per capita of the US citizen is right now more than 20 times as large as the per capita income in Ghana and Senegal, whereas over almost half a century ago the income distance between the US and these countries was a factor 8. Egypt and Morocco are countries with a slightly better track record although they too have not shown any sign of a 'catching up' process over almost fifty years. Given the large gap in income it makes sense to evaluate how economic incentives, expectations and individual characteristics, like employment status and education, affect the individual respondent's intentions to emigrate.

\section{...also for women?}

However, microeconomic motives are generally not as important for the women, as they state more often than men that family reasons are an important drive for emigration. Traditionally, the women from the Muslim countries Morocco and Senegal, have migrated mostly within the framework of family reunification, or to marry a compatriot who was already residing abroad. This road was mostly closed to Egyptian women as their husbands are more likely to live in the Gulf region, where family reunification is the exception rather than the rule. An exception 
should be made for Ghana where differences between men and women are negligible: both men and women are guided in their intentions primarily by economic reasons. Ghanaian culture does not frown upon women migrating alone, to the extent that the other three Muslim societies do, and this, combined with the greater likelihood of financial independence of women in Ghana, is likely to influence their migration perspectives and intentions.

Overall, the results of the migration surveys confirm that this motive is important for the respondents in African countries, as shown Table 1. Most of the men state economic reasons as their primary reason for intending to move abroad, whereas women are influenced by a mixture of family reasons and economic reasons. 'Economic reasons' is, however, quite a broad category of motives as it can cover up the influence of education, unemployment, poverty, wealth, search costs, to name just a few elements that enter economic theory. To unravel this motive we have tried to discern the separate effects of the most common elements of economic theory.

\section{Preferred country of destination}

In addition to the information on intentions, the survey also contains some information on the preferred country of destination of the respondents (see Table 2) and in this respect one has to conclude that preferences of potential migrants are quite different across countries but no so much within countries. Ghanaians and Senegalese by and large prefer the USA as their ultimate destination, whereas Egyptians are clearly oriented towards the Middle East, and Moroccans have their minds set at Mediterranean countries in Europe (Spain, Italy and France). These intentions partly reflect the destinations of recent emigrants, although the US tends to be somewhat more favoured among potential emigrants.

\section{Here Table 2}

To see how little preferences differ within countries Table 2 offers some suggestive statistics with respect to the geographical concentration of preferred countries of destination. Two-third of the group of potential migrants (among the non-migrants) expresses an interest in one of the top-3 countries of destination. An additional interesting finding is that the European Union (EU-15) is apparently an attractive country of destination for potential migrants from Morocco, but for Senegal and Ghana the EU attraction is moderate (50 percent choose it as their preferred destination) and in Egypt the EU is almost out of sight as a preferred destination only 13 percent expresses some interest in the EU. 
A potential factor that might explain this conformity of emigration preferences is the presence of a social network (having relatives abroad or knowing former migrants). Although the potential migrants are a subgroup who have expressed an interest in emigrating and thereby a preference for a country of destination, it stands to reason that social networks may also trigger emigration intentions as such and explain the displayed conformity of destination choice. Furthermore, networks play a crucial role in actual migration decisions and it would be of interest to see whether this also applies at the stage of forming intentions.

\section{How firm are intentions?}

Before moving on to examining the survey data in more detail one final aspect of the data should be mentioned which concerns the firmness of intentions. At this stage, it would perhaps be tempting to predict a large outflow for the surveyed countries in the near future, but putting intentions into practice is an entirely different issue. In other words, a simple 'yesno' answer to the question about the intention to move abroad does not suffice as a firm foundation for predicting a forthcoming migration move. Respondents who answered 'yes' may not be sure if or when they will actually emigrate, or they may be pretty sure about the timing of their move but have not yet taken any concrete steps.

\section{Here Table 3}

Table 3 sheds some light on how firm intentions to emigrate are. Evidently, potential migrants from Ghana are more adamant in effectuating an intended move, whereas respondents from Senegal are less adamant about their move. What is most striking of course, is the large difference between general intentions and actions taken. Partly this may be explained by the fact that as soon as people have obtained the necessary documents and funding, they do indeed migrate, leaving thus little chance for them to be included in the survey. Partly, it signifies the large discrepancy between migration intentions and migration behaviour, in the face of the obstacles people face in moving abroad.

All in all, the descriptive statistics behind the intentions to move 'out of Africa' generate some puzzles that we examine in the next sections. We are primarily interested in who leaves and who stays, and in getting some grip on this question we would like to answer, first of all, whether and to what extent the push or pull factors are responsible for triggering the high emigration intentions. Second, are there self-selection effects present at the stage of forming 
intentions, i.e. are the higher educated more eager on emigrating than the population with no or just primary education, or is it the other way around? Third, we know from actual migration decisions that social networks play a crucial role in facilitating migration, but an unresolved question in the migration literature is whether the social networks play a similar role at the stage when intentions are formed.

\section{Estimation model}

\subsection{Method of estimation}

In order to deal with the fact that migration intentions vary in intensity, as shown by Tables 3 , we will use ordered probit analysis. Ordered probit is an appropriate estimation technique when the dependent variable is categorical and ordered. For instance when people are asked whether they intend to emigrate and they respond with a 'yes', they may not be able to accurately say when they will emigrate but they surely can indicate whether they are unsure about it or whether moving abroad is a highly likely event. In other words, they can rank their probability of moving abroad. In ordered probit analysis an underlying score is estimated as a linear function of the independent variables and a set of threshold points. The probability of observing outcome $i$ (e.g., the intention to emigrate within a year) corresponds to the probability that the estimated linear score function $S_{\mathrm{j}}=\beta_{1} x_{1 \mathrm{j}}+\beta_{2} x_{2 \mathrm{j}}+\ldots \beta_{\mathrm{k}} x_{\mathrm{kj}}$ plus the random error $u_{j}$, is within the range of threshold points estimated for the outcome:

$$
\operatorname{Pr}\left(\text { outcome }_{j}=i\right)=\operatorname{Pr}\left(\kappa_{i-1}<\sum_{s=1}^{k} \beta_{s} x_{s j}+u_{j} \leq \kappa_{i}\right)
$$

where the error term $u_{j}$ is assumed to be normally distributed. With ordered probit analysis one estimates the model coefficients $\beta_{1}, \beta_{2}, \ldots \beta_{\mathrm{k}}$, along with the threshold points $\kappa_{1}, \kappa_{2}, \ldots$ $\kappa_{\mathrm{H}-1}$, where $H$ is the number of possible outcomes. In our case of explaining emigration intentions there are three threshold points as there are only four possible outcomes in constructing the intention to migrate, to wit:

(1) No intention to move abroad;

(2) Yes, but unsure when; 
(3) Yes, but over a year or more; and

(4) Yes, within a year.

The intention question also included a "don't know" option and this outcome category is left out of the analysis because it is hard to rank this category unambiguously and our interest is mainly in those respondents who express more or less clear intentions.

The estimated threshold points guide the interpretation of the estimated coefficients as they indicate how important a variable (e.g., a character trait of non-migrants) is for predicting the likelihood of moving abroad. For instance, for each observation $j$ one can calculate the score function $\left(S_{\mathrm{j}}\right)$ and the true frequency that individual $j$ will not migrate if $S_{\mathrm{j}}+u_{j} \leq \kappa_{1}$, and that he or she is unsure about the move abroad: $\kappa_{1}<S_{\mathrm{j}}+u_{j} \leq \kappa_{2}$, etc. Thus one can predict, based on the estimated coefficients, the likelihood of a particular emigration intention outcome. $^{8}$

The covariates $\boldsymbol{x}_{\mathbf{j}}$ include push and pull factors of migration. The push factors are the structural characteristics of the potential migrant and these are generally used in most migration intention studies. The pull factors are in our study the expectations concerning the net benefits of emigration. Because these variables play an important role in our estimation results some additional comments are warranted. It is highly likely that these expectations are to some extent dependent on the characteristics of the respondents. In order to cope with the independent effect of optimism on the intention to emigrate we used a two-step estimation method to separate the push (characteristics of the respondents, like education, age and sex) and pull (expected net benefits) more clearly. ${ }^{9}$ In a first stage, we regress the list of characteristics on the variables describing the expected benefits and costs to emigration. At the second stage the residuals from these regressions are entered together with the variables describing structural characteristics in a regression that explains the intention to emigrate. The residuals from the first stage, i.e. the difference between actual and predicted expectations, may be interpreted as individual-specific degrees of optimism or pessimism since they have been purged of the characteristics that might be expected to determine the individual's costs and benefits from emigration.

\subsection{Explanatory variables}

In examining the driving forces behind the emigration intentions we will use a number of explanatory variables that approximate theoretical concepts that are often used in migration and intention theory. Table 4 presents the descriptive statistics of the variables included in our 
estimations for respondents who have no experience in international migration ("nonmigrants'). The variables are primarily individually based, but there are also variables constructed at the household level, like income and household connections with (former) migrants.

\section{Here Table 4}

The striking aspect of the Table 4 is the variance in answers of the individual characteristics of the population sample across the four countries. The only exception to this rule being the expectations concerning financial gains of migration: in all countries the large majority (63 to 80 percent) of the various populations expects that emigration is a profitable move.

To focus on the most noticeable cross-country differences in Table 4 the sample population in Egypt and Ghana is relatively highly educated compared to populations of Morocco and Senegal, where approximately 75 percent of the respondents has no formal education whatsoever. The household income position of migrants differs also quite strongly as 70 percent of the non-migrants of Ghana and Senegal finds that the income is barely sufficient or plainly insufficient to buy daily necessities. The current work status differs quite distinctively across the four countries, a fact that seems to be driven primarily by the sex composition of the sample population as in Ghana, Senegal and Egypt the women dominate the population and only in Morocco men dominate the sample of non-migrants. Furthermore, in Muslim countries like Egypt the labour market status of women is concentrated mainly outside the labour market, viz. inside the home. This status contrasts with that of women in a country like Ghana where they are actively participating in gainful employment.

The cultural differences across countries are also reflected in the answers to the question whether respondents approve of unmarried women migrating abroad for a couple of years. To capture the state of 'modernity' in African countries and its effect on migration the question was asked "Would you approve or disapprove of a young unmarried woman moving abroad to work there for a couple of years?" and as one can see from Table 4 Ghana is clearly the most tolerant among the four as two out of three respondents approves of single women migrating. Egypt is the mirror image of Ghana where 94 percent of the respondents disapproves of single women migrating. The other two countries are more divided on this question. It should, however, be pointed out that the sample means for this question for this question are affected by the sex composition (not shown here) of the various samples and therefore can cover up considerable differences. E.g., the disapproval rate in Senegal is 44 
percent, but when one considers the differences across sexes it turns out that 53 percent of the men disapproves of single women migrating and 39 percent of the wo men disapproves such moves. Similar figures can be presented for Morocco, where respectively 58 and 33 percent of the men and women disapprove of single women moving abroad. In Ghana men and women are more alike in approving migration of single women, and the same consensus can be said to exist in Egypt albeit that the attitude towards single women migrating is completely reversed.

Another cultural question that is often mentioned in intentions research is a question that captures the sense of self-efficacy. The question "Do you think that in general it is possible for people to determine what happens in their lives, or do you think it is mostly up to fate?" generates quite strong differences across countries: in Ghana the large majority thinks it is possible to determine what happens, whereas in the other three countries the large majority thinks it is up to fate, with Egypt as the most traditional society where 90 percent thinks it is not possible to determine outcomes in life.

\section{Expected Signs}

With respect to the model coefficients $\beta_{\mathrm{i}}$ there are a number of predictions one can make based on migration (intentions) theory. First of all, one would expect age to be of influence as because the decision to emigrate involves a sense of flexibility and large investments (some of which are pecuniary, whereas other investments are less tangible) and this investment has to be recouped over the rest of the life course. One would therefore expect that emigration is concentrated among the young as they are the ones who have not yet settled down and who have few commitments. Most of them have not yet invested much in home-country-specific capital as their middle aged and older compatriots, thereby making it possible for them to switch countries, or at least consider switching countries as is the case in our survey.

With respect to ties such as those embedded in the marital status or the ties within the household with current or return migrants one would expect to detect some influence on the intentions. Ties with a spouse or a former spouse signal that the respondent is less mobile than someone who has never been married. Furthermore, given the fact that traditional values about the role of women in society in quite a number of African countries are still quite dominant, one would expect women to be more hesitant in expressing intentions to emigrate as it are the men who often take the lead in migration, to be followed in time by their spouses. Traditions are also reflected in the sense of self-efficacy and intention theory would predict that those with a higher sense of self-efficacy are on average more set on moving abroad or 
having more concrete plans than other potential migrants who lack this sense. Of course, measuring such a general attitude does not automatically apply to the case of emigration, it could just as well apply to any other decision process.

Social network ties can be an important driving force in triggering emigration. It has been stressed in the literature that network ties across countries are extremely important as they lower the costs of adjustment for potential migrants (see e.g. Massey et al., 1998, Curran and Rivero-Fuentes, 2003). Emigrants often use their relatives in searching for a house and a job in the country of destination and barriers imposed by a foreign language can to some extent be circumvented by using the family network as contacts outside the network are sometimes minimal. To capture part of the network effects that are often stressed in migration decision making, we include a variable that characterises the household in which respondents live. We distinguish four types of households: (1) households consisting of non- migrants only (our benchmark household type), (2) households consisting of non-migrants and one or more return migrants, (3) households consisting of non- migrants and one or more current migrants; and (4) mixed migrant households in which non- migrants, return and current migrants are present. The reason for including this variable is that the presence of a household member with a current or past migration experience may affect potential migrants in the household to consider to also emigrate or at least affect the firmness of stated intentions. Return or current migrants in a household generally convey information on the pros and cons of emigration. $A$ priori we may expect that such information is more readily available in households with migrants than in those without. However, it is not clear how the direction and the magnitude of the different network connections will affect stated intentions. Return migrants are different from non-migrants as their information is coloured by their experience and this experience might be either positive or negative. By the same token, current migrants whose information on finding jobs or housing is more up-to-date might just as well be positive of negative. Therefore, the mixed migrant household can be expected to be in a better position to inform potential migrants as different types of information are available.

The element of education can play a prominent role as the theory of adverse selection has made abundantly clear. However, the empirical literature on migration is ambiguous about the importance and strength of selection effects. Borjas $(1987,1991)$ comes up with strong selfselection effects, suggesting that primarily the lower skilled migrants are the ones who leave their country and enter the US, whereas Chiquiar and Hanson (2002) find ambiguous effects or effects that contradict Borjas' findings. Although the nature of our data is quite different - 
emigration intentions - it would be of interest to see whether the attained level of education has an independent effect on intentions. In other words, can one discern a self-selection effect at the stage when intentions are formed? The higher educated are perhaps the ones who are better informed about making a move abroad. Furthermore, the higher educated may generally be the ones who are sponsored by their family to go abroad as they are believed to have a better chance of making a living, of which those who stay behind can also profit by means of financial remittances (see Groenewold and Fokkema, 2002). The only comparable research on this topic (based on intention data) is the work Drinkwater (2002) and Liebig and Sousa-Poza (2004) who draw on the same database. The latter make even the rather bold claim based on their findings that positive self-selection "can be generally expected in international migration" (2004: 126).

Income is another ambiguous variable as being well off can signal that a respondent can afford the costs of migration as well as a stimulus to stay at home and the reverse applies, of course, to those who live in poverty: poverty can be an important stimulus to emigrate but at the same time it implies that one can be liquidity constrained and financing of the migration costs may well prove prohibitive.

Finally, we have controlled the regressions for the type of regions in which respondents were living. The survey sample was created along two dimensions - migration history and level of economic development - so the data offer us an opportunity to explore the influence of regional contexts. One of the reasons for using this distinction is to evaluate whether the level of economic development comes into play and whether there are traces of a 'migration culture' in stating migration intentions. It can be hypothesised that where migration is still a recent and relatively rare phenomenon, migration intentions might still be weak, as the idea of migration has not yet taken a firm hold. In a region with a long and established migration history going abroad may perhaps have become a 'rite of passage', whereas in recent migration regions the intention to move is still an adventurous and daring move and because it is such a daring move one would expect that network ties abroad exert a larger effect on emigration intentions in this region than in a region with a more established history of migration. The reference category is the region with a long or established history of emigration and a more developed status of economic development. The other regions are: more developed but with a recent migration history; less developed with an established migration history; and less developed region with a recent migration history. 


\section{Estimation}

Table 5 presents the estimation results for the non- migrant population of working age (18-65 years) in the four African countries. To make the separate contribution of expectations explicit we present two models per country: model 1 simply presents a reduced form model in which intentions are conditional on a number of individual characteristics; and model 2 extends the previous model by including variables that approximate the individual-specific optimism with respect to the net benefits tied to emigration. Before we move on to discussing the estimation results it should be pointed out that adding individual specific expectations to the equation improves the explanatory power of model 1 quite distinctively. In summing up the driving forces behind the pressure to emigrate we will discuss the explanatory variables as they appear in Table 5.

\section{Here Table 5}

Age

Most emigration studies reveal that emigrants are young and the results in Table 5 confirm this finding: the older a respondent is, the less likely he or she will state an intention to emigrate. Furthermore, one can also distil from the data the fact that the older one gets the firmer this intention becomes, i.e. the standard deviation declines steadily with increasing age. Both findings are in accordance with theory and related research.

\section{Sex and marital status}

The coefficients with respect to sex suggest that there are strong differences in expressing intentions in Morocco, Senegal and Egypt, whereas in Ghana the differences between males and females are relatively low.

The ties implied by the marital status variable plays no role in determining emigration intentions. Only in Senegal can one trace some influence of the marital status, where being single triggers respondents to be more set on emigrating than those with marital ties. The absence of an effect of marital status is, however, somewhat puzzling. Part of the solution to this puzzle may be traced to the different (marital) roles played by men and women in African societies. The differences in decision making across men and women is already captured in the gender dummy and not by the marital status variable. In section 6 we will explore the issue of gender differences in more detail. 


\section{Education}

The effect that education has on emigration intentions is ambiguous if one takes a look at the estimation results for the four countries. Education clearly has a significant effect on the intention to emigrate in Ghana and Egypt: the effect on the intentions of those respondents with a higher education is twice as large as the intentions of those with a primary education. In short, judging from these intentions data there does appear to be some positive selfselection effect present even before migration steps are actually taken. However, the positive self-selection of potential migrants does not appear to be a universal phenomenon. Negative self-selection is present in Morocco where the intention to move abroad is higher among uneducated respondents compared to those with primary school. Senegal is again somewhat different as non-migrants with a higher education display lower intentions than respondents with no education but respondents with a primary school diploma are more set on migrating than the uneducated. The negative selection effect of education in Senegal must, however, not be overstated as 95 percent of the respondents has only a primary education or no education at all.

\section{Evaluation of the present income position}

One would also expect that the income evaluation (representing a push factor to emigrate) would be a major driving force in the different African countries. To capture the income situation of individuals the question was asked: "Overall, is the financial situation of the household more than sufficient, sufficient, barely sufficient, or insufficient to buy all the basic needs?" An insufficient income position could be a sound reason for emigration and as Table 5 clearly shows this is indeed the case for Ghana, Morocco and Egypt: compared to nonmigrants who considered the income of their household sufficient, the intention to emigrate for those with an insufficient income position is significantly positive. One exception to this rule should be mentioned out as those well-off in Ghana are more set on emigrating than the base category, households with sufficient income. Furthermore, poverty does not seem to be a general driving force to emigrate as the income level seems to play no role of importance in Senegal.

\section{Current work status}

The work status is a variable that affects migration intentions in a number of ways. Naturally, being unemployed is a status that may trigger thoughts of a move abroad and indeed the unemployed - even though the (unweighted) unemployment percentage in the population 
sample varies from three to eight percent - are far more set on moving abroad, especially in Morocco, than the reference category - employees (or casual workers). For the unemployed migration clearly offers an alternative route to gainful employment. For those who are already active on the labour market, the calculus of migration is more complex. As one can see owners of a business or employers are less set on moving abroad than employees, which is quite understandable as employers, c.q. owners of businesses are more or less tied to their home country and moving abroad would involve large adjustment costs. Workers (casual labourers, employees or unpaid family workers) are in that respect far more flexible as they do not own physical assets that have to be sold in case of emigration. The fact that students do not differ much from the reference category (only in Ghana can one detect a weak negative effect) is perhaps also surprising as most studies of a brain drain would make one expect that students are dead set on moving to the US or Europe.

\section{Household connections}

The estimated coefficients in Table 5 show that the network effect exerts a clear positive influence on the intention to emigrate in Ghana and Egypt. In line with the hypothesis that mixed households convey more information than households with either current migrants or return migrants, the Egyptian respondents belonging to mixed household are somewhat more inclined to emigrate than those belonging to a current or a return migrant household. The mixed migrant household is, however, not such a widespread phenomenon in the samples of these countries (1 percent and 9 percent, respectively). Current migrant households are the more common type.

The fact that network effects are not present in Morocco and Senegal casts doubt about the general claim in many migration studies that network effects are an important driving force. ${ }^{10}$ Because the absence of an effect is quite noteworthy we would like to put forward a number of reasons why strong network effects do not show up in our micro-data.

First of all, we are dealing with intentions and not actual migration steps. Apparently, in the case of stating an intention to emigrate it is not so important to have connections as it is when actual migration steps are undertaken. It should, however, be noted that among the migrants who have a plan to migrate, in the case of Ghana, we do see a clear effect of networks on increasing the probability to migrate within the year.

A second explanation for the weak network effects may be the measurement of the network ties. However, in testing for the presence of network effects we have also used 
alternative measures, such as the presence of a family member (brother, sister, parent or child) abroad, and this variable yielded similar weak results.

A third explanation for the weak effect of network ties is perhaps the most plausible one and this explanation amounts to the existence of a migration culture in certain localities or regions. The effect of a genuine migration culture would be that everyone - young and old, poor and rich, skilled and unskilled - would move if they had the chance. From field studies we know that in particular in Morocco and Ghana this type of migration culture exists. In the case of Morocco policy makers explicitly use emigration policy as a strategy to cope with the high unemployment and simultaneously benefiting from the benign effects of remittances migrants send to their family. For the case of Senegal such a general migration culture does not exist. However, the estimation results in Table 5 suggest for Senegal in particular that migration intentions are clearly higher in the established migration region of Dakar and Pikine compared to the region with a short history of migration of Diourbel and Tourba. This may be the alternative explanation why household ties are not so important in Senegal as the ties of the local population in the established migration region may be just as important in triggering intentions to emigrate. The coefficients of the regional dummies in the other countries provide us with no clear picture of the influence of regional migration history or the level of development.

\section{Norms and values}

In estimating the models of Table 5 the effect of norms surrounding emigration are of some importance, especially the attitude related to the possibility of single women migrating is clearly reflected in intentions in each and every country. Given the fact that Ghana is the most modern of the four African countries (only 18 percent of the Ghanaian population disapproves of single women migrating) it is perhaps not such a surprise that emigration intentions are also the highest of these four countries.

The sense of self-efficacy is an entirely different story as this variable does not give such unambiguous effects: this attitude exerts an extremely weak effect in triggering migration intentions in Senegal and Morocco. And in Ghana and Egypt migration intentions are unaffected by this sense of self-efficacy. However, the absence of an effect or the presence of weak effects are understandable as we mentioned earlier that the sense of self-efficacy may well refer to other decision processes and not migration decisions in particular. To rephrase the argument: people can have a high sense of self-efficacy but still be set on staying in the 
home country as they, for instance, think that they can make things happen in business or some gainful employment at home.

\section{Optimism about net benefits of migration}

To capture the influence of expectations we have included the answers to the question: "Do you think that moving abroad could improve your financial situation?" in model 2. As we explained earlier, these expectations are purged from interdependencies with the other explanatory variables by following a two-step estimation procedure. The first stage regression results are not presented here to keep the analysis as brief as possible. ${ }^{11}$ To mention just a few of the most salient outcomes of these first stage regressions: age and attitudes about single women migrating affect expectations negatively in all countries, i.e. the young have higher expectations than the old and 'modern' citizens have higher expectations than more 'traditional' citizens. The effect of regional location of respondents affects their expectations only in Ghana and Egypt, where respondents who are located regions with a recent migration history have higher expectations than those situated in more established regions.

With the help of these first stage regressions we constructed a measure of optimism of non-migrants by taking the difference between stated and predicted expectations. For each and every country the population is skewed towards the optimistic expectations, i.e. most respondents' expectations exceed their predicted value. And as one can deduce from Table 5 the optimism concerning financial gains tied to a move abroad is indeed a major driving force behind the intention to emigrate: the coefficients are, for each and every country, large and statistically significant. This effect clearly is important as the large majority of the respondents (between 64 and 80 percent, see Table 4) expect that moving abroad will improve their financial situation. ${ }^{12}$

Besides the optimism surrounding the gains there are also costs involved in moving abroad and one of those costs represents job search costs. In the survey the following question was asked: "Where do you think it is easier to find a job: in this country of in a European country? Respondents could choose between the options: (1) in this country, (2) both equally easy; or (3) in a European country. The same two-step estimation procedure is applied in the case of the expected financial gains question and again one should interpret the explanatory variable in terms of optimism (or pessimism). On the whole, most non-migrants in Ghana, Morocco and Senegal expect that finding a job in Europe is easier than in their home country. Non-migrants in Egypt are the exception to this rule, a divergence that seems to be directly related to the fact that the preferred country of destination does not coincide with Europe. 
Most potential emigrants in Egypt are not focused on Europe at all but the Middle East, and the same applies to a lesser extent for Ghana where the US is the most popular country of destination. However, even though the question may not be relevant to all respondents the stance that is reflected in the expectations of finding a job in Europe does reveal something about their outlook. This optimistic stance is also reflected in the estimates of Table 5: respondents in Egypt who think finding a job in Europe is easier than in Egypt are particularly motivated to emigrate.

\section{Gender Differences in Migration Intentions}

Estimating relationships like those in Table 5 can cover up differences if groups differ considerably in their intentions. An important group distinction, certainly in the context of traditional African countries, is the one delineated by sex. One of the most striking and robust aspects of our migration research is that African men and women have different emigration intentions and this can be easily deduced from the estimation results of Table 5 where the dummy variable sex has large coefficients in traditional countries like Morocco and Egypt. Clearly, the cultural context of different countries affects migration decisions and this is relevant in Islamic countries, where it is generally less accepted that single women emigrate independently, or for married women to migrate alone leaving their husband and children behind. In these countries, as mentioned earlier, independent migration of women, not within the context of the family, is uncommon and generally frowned upon. The more generally accepted alternative of family reunification migration is rarely an option for Egyptian women whose husbands generally work in the Gulf region. Family reunification is in principle open to Senegalese women with husbands in Europe, although usually only for one of the wives in case of polygamous marriages; and for the wives of recent, often undocumented migrants, migration is not a very viable option either.

\section{Here Table 6}

To take account of gender differences in emigration we have re-estimated model 2 of Table 5 for both men and women and the results are presented in Table 6. In re-estimating the model for the different samples of men and women a number of points stand out. ${ }^{13}$ First of all, men seem to be led by the great financial expectations and low job search costs in stating their intentions. 
Secondly, the intentions of women are led to a lesser degree by these financial expectations of emigration compared to those of men. This is in line with what Vogler and Rotte (2000) find for panel data on immigration flows from 86 African and Asian countries: men react more strongly than women on economic factors. The really important factors in affecting intentions of women are networks, education, the household income position and the adoption of values that fit the western world (approximated by the attitude towards unmarried women moving abroad). The effect which self-efficacy can have on intentions is ambiguous as it matters only to some extent for men in Senegal. Furthermore, the effect is quite small, suggesting that potential emigrants do not seem to possess a typical psychological character trait that would make them successful in the countries of destination.

Thirdly, the marital status does not have an effect on the intentions of either men or women. As we mentioned earlier in section 5, one would expect a priori the marital status to be of some significance as those who are single have no ties with a (former) spouse or children and have the advantage of being flexible. In answering the intention question they may therefore contemplate emigration more often as a viable option. The estimation results defy this logic. However, the absence of an effect for men can be completely in line with dayto-day experience and tradition of Muslim African societies where men take the lead in decision making. Being married should in that respect not be a factor of importance for men in considering the decision to move or to stay. For women the absence of an effect represents more of a puzzle, as their intention to move abroad would depend on their husband's choice. One reason why marital status does not exert an independent effect on migration decisions of women (except for Senegalese women) is that for them emigration is not a free choice when they are single - society does not condone it - nor when they are married - they either follow their husband abroad or they stay behind and live on the remittances that are sent back home. The fact that marital status does not affect intentions in an independent manner may to some extent also be explained by the fact that some background variables, like age, already cover the influence of marital status.

Finally, the effect that education has on emigration differs clearly across men and women and thereby sheds some interesting light on the relevance of self-selection theories as these theories generally do not pay attention to gender roles; roles which evidently are important for understanding migration flows and structures as Table 6 shows. The positive self-selection effect for Ghana in Table 5 was clearly driven by the fact that this selection effect applies only for Ghanaian women, whereas education does not exert a notable force on the intentions of men. To a lesser extent the same can be said of Egypt, although positive self-selection is 
present both among women and men. The reverse case applies to Morocco where negative self-selection applies solely to the intentions of men and education plays no role at all for women. In Senegal one can detect only a weak case of positive self-selection for men.

\section{Conclusion and Discussion}

Who leaves Africa? And what forces drive them out of Africa? Is it the lure of the rich West or is it the poverty and the loss of future of Africa that drives people across the border? Simple as these questions may sound, they have received different answers and unfortunately there is only scarce micro-evidence on the importance of the various factors that are at play in Africa. Still the importance for gaining a quantitative insight into this question is building up as Africa is one of the continents that will influence global migration flows for the next fifty years (see, e.g., United Nations, 2002, and Hatton and Williamson, 2003b).

Based on migration surveys that were held in four African countries (Ghana, Senegal, Egypt and Morocco) in the period 1997/1998 we show how high the emigration intentions are and what drives these intentions. The survey data show clearly that the emigration pressure is high in some countries (Ghana, Senegal), whereas in a country like Egypt the 'pressure' (i.e. emigration intentions) does not seem to take on dramatic proportions. What seems to be clear across the countries considered is that emigration 'out of Africa' is the dominant stated preference and that the typical potential migrant is young, male, and someone who has modern values, but if one had to sum up what dominates the pressure to emigrate 'out of Africa', it would be just two words: great expectations. The intention to emigrate is clearly driven - in all four African countries - by economic motives and expectations, especially among young men. The expectations of financial gains tied to migration together with an optimistic view of finding a job in the country of destination influences the intention to emigrate in all four countries quite heavily. What is perhaps noteworthy is that men give more weight to the argument of expected financial gains of emigration than women. Although this is completely in line with what one would expect, the force of expectations on emigration intentions is quite strong and, as far as we know, for empirical international migration studies it is a novel element. This particular insight underscores the theoretical analysis of O'Connell (1997) on migration decision- making under conditions of uncertainty.

However, besides these general observations, one cannot distil more encompassing stylized 'facts' of migration. 'Who leaves?' is perhaps a simple question, in practice it is a question that is extremely difficult to answer as each and every country is characterised by specific elements that seem to trigger emigration (intentions). The roles played by education, 
income position and labour force status in forming intentions are not as robust and as overwhelming as the previously mentioned expectations and the demographics of age and sex. Poverty is a driving force as well as being unemployed in most countries, but none of these findings should be treated as an ironclad rule. Each country tells a different story. For instance, poverty (as measured by an insufficient income position) does not play a role of importance in Senegal, unemployment is not a notable driving force in Egypt and Ghana. Self-efficacy plays no distinguishable role in Ghana, Morocco and Egypt and finally the effect of education on migration intentions is completely ambiguous. Close inspection of the effect of education for both men and women reveals that strong positive self-selection effects are only present among Ghanaian and Egyptian women. The evidence for men is mixed: positive self-selection only applies to Egyptian and (to some extent) Senegalese men, negative selfselection is even present among Moroccan men and the education of Ghanaian men does not affect their intentions.

A last finding that needs to be included in this conclusion is that social network effects leave their mark in increasing the intention to emigrate but not as much as one would expect. In Ghana and Egypt the effect of having a household member who has been an international migrant or who still is a migrant is clearly important and exerts a strong force on the intentions of potential migrants. But given the fact that social network effects on intentions are virtually absent in Senegal and Morocco, this casts some doubts about the general importance of social network effects for migration intentions. This finding contrasts strongly with the actual practice of migration where networks have proven to a be a structural driving force. One reason why this may be so is that either the formulation of intentions is an entirely different issue than realising intentions and actually emigrating; or emigration in countries like Morocco and Ghana are heavily influenced by a nation-wide migration culture. The case of Senegal may perhaps be the result of region-specific migration culture.

Now what do these findings imply for the future of these countries and the countries of destination? In our introduction we cited some opinions of well-informed economists on the future of Africa and they were not particularly optimistic. The migration pressure is real and will be hard to redress. Hatton and Williamson (2002) conclude their review of migration forces in our world of today by making the following (under)statement: "if OECD countries think they have an immigration problem now, they are going to find the future even more challenging." The ultimate question is, of course, whether the prime forces that trigger emigration (and the underlying intentions) might also diminish this pressure in the near future. Immigration countries - both the traditional immigration countries like USA and Australia, 
but also countries in Europe - are grappling with the consequences of immigration and a slower pace of immigration would seem more desirable as the institutions and citizens in most of these countries can adjust to accommodate the inflow of immigrants. As far as one can rely on intentions as predictors of future behaviour, the estimation results do make clear that the emigration pressure will not subside for a considerable time. First of all, it takes time for economic prospects in these African countries to improve and once they have improved closing the gap between African and Western standards of living will be difficult if not impossible. And secondly, we know from actual migration experience that the transnational networks turn out to have an important effect on emigration decisions. In short, it are these forces (great expectations about economic gains, poverty, a relatively young age structure and social networks) that will stimulate emigration out of Africa for years if not decades to come, whereas the most important countervailing force (strong catching up processes in the African economies) lacks credibility and will probably not affect the expectations of populations in a significant manner for years to come.

\section{References}

Ajzen, I., 1985, From Intentions to Actions: A Theory of Planned Behavior, in: J. Kuhl and J. Beckmann (eds.), Action Control, Springer Verlag, Berlin, pp. 11-40.

Ajzen, I., 1988, Attitudes, Personality, and Behaviour, Open University Press, Milton Keynes. Bhagwati, J.N. (ed.), The Brain Drain and Taxation: Theory and Empirical Evidence, Vol. II, North Holland, Amsterdam.

Blanchard, O.J., 2002, Final remarks, in: T. Boeri, G. Hanson and B. McCormick (eds.), Immigration Policy and the Welfare System, Oxford University Press, Oxford, pp. 310-313.

Bloom, D. and J.D. Sachs, 1998, Geography, Demography, and Economic Growth in Africa, Brookings Papers on Economic Activity, volume 1998: 207-273.

Borjas, G.J., 1987, Self-Selection and the Earnings of Immigrants, American Economic Review, 77: 531-553.

Borjas, G.J., 1991, Immigration and Self-Selection, in: J. Abowd and R. Freeman (Eds.), Immigration, Trade and the Labor Market, Chicago University Press, Chicago, 29-76. . Borjas, G.J., 1994, The Economics of Immigration, Journal of Economic Literature, 32: 1667-1717. 
Burda, M.C., W. Härdle, M. Müller, and A. Werwartz, 1998, Semiparametric Analysis of German East-West Migration Intentions: Facts and Theory, Journal of Applied Econometrics, 13: 525-541.

Chiquiar, D., and G.H. Hanson, 2002, International Migration, Self-Selection, and the Distribution of Wages: Evidence from Mexico and the United States, NBER Working Paper, 9242, Cambridge MA.

Chiswick, B.R., 1999, Are Immigrants Favorably Self-Selected?, American Economic Review, Papers and Proceedings, 89: 181-185.

Collier, P., and J.W. Gunning, 1999, Why Has Africa Grown Slowly?, Journal of Economic Perspectives, 13: 3-22.

Curran, S.R., and E. Rivero-Fuentes, 2003, Engendering Migrant Networks: The Case of Mexican Migration, Demography, 40: 289-307.

De Jong, G.F., 2000, Expectations, Gender, and Norms in Migration Decision-Making, Population Studies, 54: 307-319.

De Jong, G.F., K. Richter, and P. Isarabhakdi, 1996, Gender, Values, and Intentions to Move in Rural Thailand, International Migration Review, 30: 748-770.

Drinkwater, S., 2002, Go West? Assessing the Willingness to Move from Central and Eastern European Countries, mimeo, University of Surrey.

Faini, R., 1999, European Migrants: An Endangered Species?, in: R. Baldwin, D. Cohen, A. Sapir and A. Venables (Eds.), Market Integration, Regionalism and the Global Economy, Cambridge University Press, Cambridge, pp. 228-251.

Fawcett, J.T. (ed.), 1986, Migration Intentions and Behavior - Third World Perspectives, Population and Environment, vol. 8, nrs. 1-2. Special issue.

Fishbein, M., and I. Ajzen, 1975, Belief, Attitude, Intention and Behavior, Addison-Wesley, Reading, MA.

Gallup, J.L., J.D. Sachs, and A.D. Mellinger, 1998, Geography and Economic Development, NBER Working Paper, no. 6849, Cambridge, MA.

Gardner, R.W., G.F. de Jong, F. Arnold, and B.V. Carino, 1986, The Best-Laid Schemes: An Analysis of Discrepancies Between Migration Intentions and Behavior, Population and Environment, 8: 63-77.

Gordon, I.R., and I. Molho, 1995, Duration Dependence in Migration Behaviour: Cumulative Inertia versus Stochastic Change, Environment and Planning A, 27: 1961-1975. 
Groenewold, G., and T. Fokkema, 2002, Receipt of Remittances and Their Effects on Emigration Intentions in Egypt, Morocco and Turkey, Report for the Dutch Ministry of Foreign Affairs, NIDI, The Hague.

Hatton, T.J., and Williamson, J.G., 2002, What Fundamentals Drive World Migration?, NBER Working Paper, no. 9159, Cambridge, MA.

Hatton, T.J., and Williamson, J.G., 2003a, Demographic and Economic Pressure on Emigration out of Africa, Scandinavian Journal of Economics, 105: 465-486.

Hatton, T.J., and Williamson, J.G., 2003b, Out of Africa?: Using the Past to Project African Emigration Pressure in the Future, Review of International Economics, 10: 556-573.

Hughes, G.A., and B. McCormick, 1985, Migration Intentions in the UK - Which Households Want to Migrate and Which Succeed?, Economic Journal, 95: 113-123.

Katz, E., and O. Stark, 1987, International Migration under Asymmetric Information, Economic Journal, 97: 718-726.

Kuyvenhoven, A., 1997, Out of Africa, Economisch Statistische Berichten, 82: 101

Liebig, T., and A. Sousa-Poza, 2004, Migration, Self-Selection and Income Inequality: An International Perspective, Kyklos, 57: 125-146.

Lu, M., 1999, Do People Move When They Say they Will? Inconsistencies in Individual Migration Behavior, Population and Environment, 20: 467-488.

Manski, C.F., 1990, The Use of Intentions Data to Predict Behavior: A Best-Case Analysis, Journal of American Statistical Association, 85: 934-940.

Massey, D.S., J. Arango, G. Hugo, A. Kouaouci, A. Pellegrino and J.E. Taylor, 1998, Worlds in Motion - Understanding International Migration at the End of the Millennium, Clarendon Press, Oxford.

Mincer, J., 1978, Family Migration Decisions, Journal of Political Economy, 86: 749-773.

O’Connell, P.G.J., 1997, Migration Under Uncertainty: "Try Your Luck" or "Wait and See”, Journal of Regional Science, 37: 331-347.

Papapanagos, H., and P. Sanfey, 2001, Intention to Emigrate in Transition Countries: The Case of Albania, Journal of Population Economics, 14: 491-504.

Rotte, R., M. Vogler, and K.F. Zimmermann, 1997, South-North Refugee Migration: Lessons for Development Cooperation, Review of Development Economics, 1: 99-115.

Sandu, D., and G.F. De Jong, 1996, Migration in Market and Democracy Transition: Migration Intentions and Behaviour in Romania, Population Research and Policy Review, 15: 437-457. 
Schoorl, J., L. Heering, I. Esveldt, G. Groenewold, R. van der Erf, A. Bosch, H. de Valk and B. de Bruijn, 2000, Push and Pull Factors of International Migration - A Comparative Report, Eurostat, Luxembourg.

Simon, J.L., 1989, The Economic Consequences of Immigration, University of Michigan Press, Ann Arbor.

Sjaastad, L.A., 1962, The Costs and Returns to Human Migration, Journal of Political Economy, 70: 80-93.

Stark, O., 1991, The Migration of Labor, Basil Blackwell, Oxford.

Tunali, I., 2000, Rationality of Migration, International Economic Review, 41: 893-920.

United Nations, 2002, World Population Prospects, UN, New York.

Van der Erf, R., and L. Heering, 2002, Moroccan Migration Dynamics: Prospects for the Future, IOM Migration Research Series, no. 10, Geneva.

Vogler, M., and R. Rotte, 2000, The Effects of Development on Migration: Theoretical Issues and New Empirical Evidence, Journal of Population Economics, 13: 485-508.

White, H., 1980, A Heteroskedasticity-Consistent Covariance Matrix Estimator and a Direct Test for Heteroskedasticity, Econometrica, 48: 817-830.

Yang, X., 2000, Determinants of Migration Intentions in Hubei Province, China: Individual versus Family Migration, Environment and Planning A, 32: 769-787. 


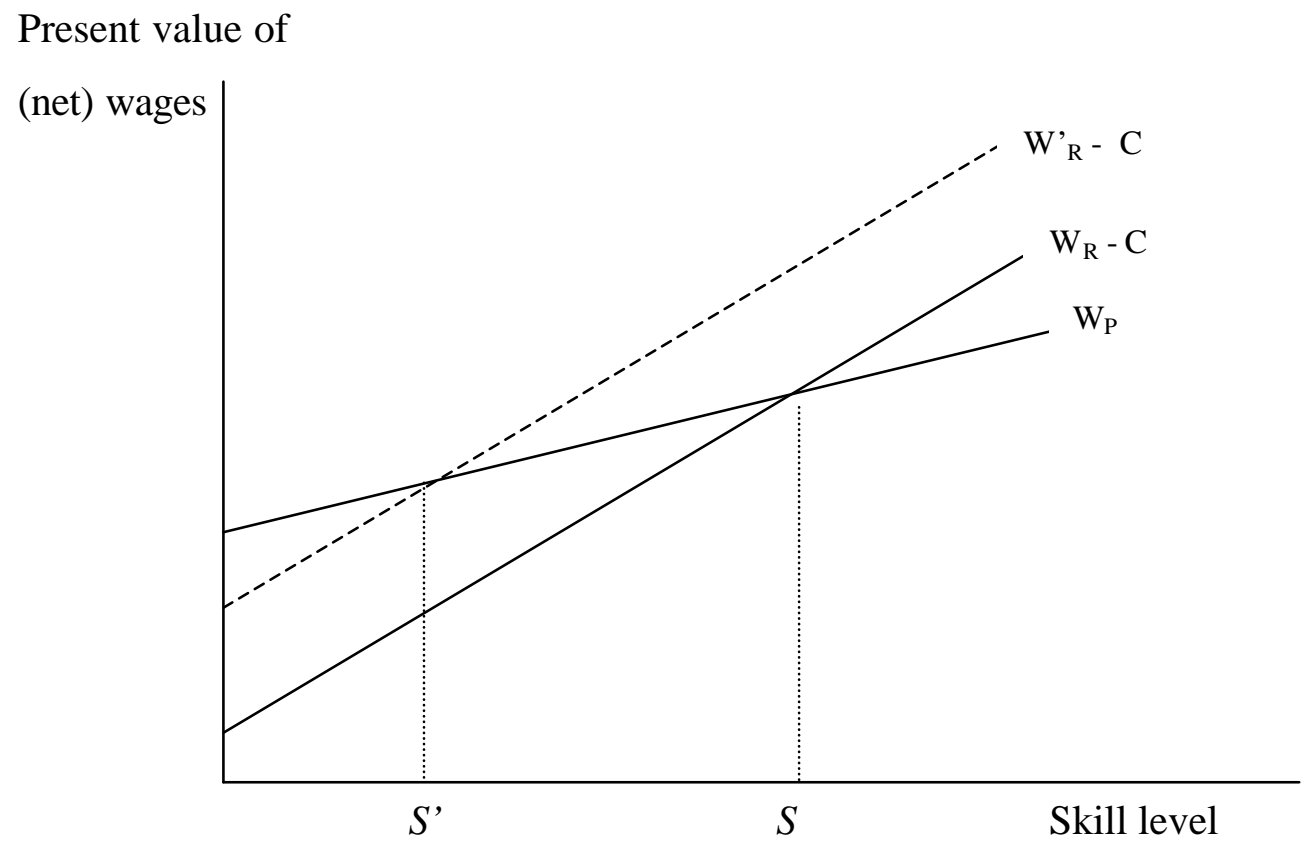

Figure 1: Migration, expectations and self-selection of the skilled

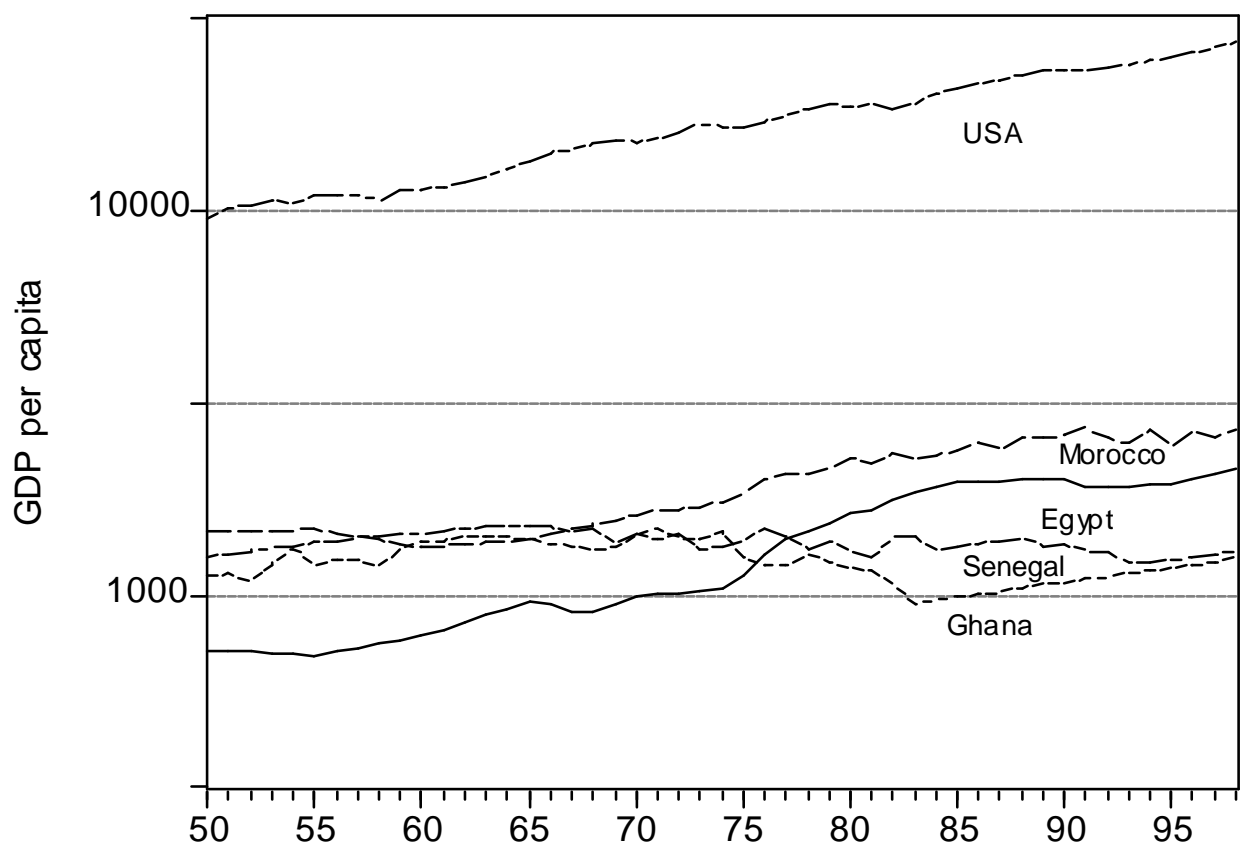

Figure 2: GDP per capita US versus African countries, 1950-1998 (1990 dollars, logarithmic scale) 
Table 1: Who wants to emigrate (or not) and why?

\begin{tabular}{|c|c|c|c|c|}
\hline & \multicolumn{4}{|c|}{ Potential emigrants from $(\%)$ : } \\
\hline & Ghana & Morocco & Senegal & Egypt \\
\hline Intention to migrate & 41 & 20 & 38 & 12 \\
\hline \multicolumn{5}{|l|}{ Motivation to } \\
\hline \multicolumn{5}{|l|}{ emigrate: } \\
\hline Economic reasons & 79 & 91 & 89 & 83 \\
\hline Family reasons & 5 & 5 & 3 & 9 \\
\hline Other reasons $^{\mathrm{a}}$ & 15 & 5 & 8 & 8 \\
\hline Total & 100 & 100 & 100 & 100 \\
\hline \multicolumn{5}{|l|}{ Motivation to stay: } \\
\hline No financial needs & 10 & 33 & 6 & 9 \\
\hline Lack of means & 23 & 4 & 14 & 1 \\
\hline Family reasons & 23 & 30 & 40 & 64 \\
\hline Other reasons ${ }^{\mathrm{b}}$ & 45 & 32 & 40 & 27 \\
\hline Total & 100 & 100 & 100 & 100 \\
\hline
\end{tabular}

Source: Schoorl et al. (2000), weighted data.

(a) Other reasons refer to education, adventure, fear of persecution, etc.

(b) Other reasons refer to old age, legal problems of emigration, do not like living abroad, etc.

Table 2: Top-3 of preferred countries of destination

\begin{tabular}{lcccc}
\hline Popularity of preferred country of & \multicolumn{4}{c}{ Potential migrants from: } \\
\cline { 2 - 5 } destination & Ghana & Morocco & Senegal & Egypt \\
\hline First place & USA & Spain & USA & Saudi Arabia \\
Second place & Germany & Italy & Italy & Kuwait \\
Third Place & UK & France & France & United Arabic Emirates \\
Cumulative percentage no. 1-3 & 65 & 67 & 69 & 71 \\
Cumulative percentage EU -countries & 44 & 98 & 48 & 13 \\
\hline
\end{tabular}

Source: Schoorl et al. (2000: 120), weighted data, and own calculations.

Table 3: How firm are the intentions to emigrate?

\begin{tabular}{lcccc}
\hline & \multicolumn{3}{c}{ Potential migrants from (percentages): } \\
\cline { 2 - 5 } & Ghana & Morocco & Senegal & Egypt \\
\hline Intention to emigrate & 41 & 20 & 38 & 12 \\
Intention to emigrate within two years & 13 & 4 & 5 & 1 \\
Has taken actual steps to emigrate & 8 & 3 & 2 & 0 \\
\hline
\end{tabular}

Source: Schoorl et al. (2000), weighted data 
Table 4: Descriptive statistics, unweighted sample means (18-65 years)

\begin{tabular}{|c|c|c|c|c|}
\hline Dependent variable - emigration intention & Ghana & Morocco & Senegal & Egypt \\
\hline No intentions & 51.9 & 71.4 & 63.6 & 87.2 \\
\hline Yes, but unsure when & 25.9 & 21.5 & 30.6 & 9.8 \\
\hline Yes, after more than one year & 11.5 & 4.4 & 3.3 & 2.0 \\
\hline Yes, within a year & 10.7 & 2.7 & 2.5 & 1.0 \\
\hline \multicolumn{5}{|l|}{ Independent variables: } \\
\hline Age (in years) & 34.0 & 41.7 & 33.9 & 36.9 \\
\hline Sex-Female & 57.9 & 28.1 & 58.6 & 72.9 \\
\hline \multicolumn{5}{|l|}{ Marital status } \\
\hline Single & 34.0 & 17.8 & 30.8 & 20.2 \\
\hline Ever married (married, divorced, widowed) & 66.0 & 82.2 & 69.2 & 79.8 \\
\hline \multicolumn{5}{|l|}{ Education (level achieved) } \\
\hline No education & 14.5 & 74.8 & 77.2 & 55.6 \\
\hline Primary & 54.3 & 14.4 & 17.3 & 14.3 \\
\hline Secondary & 25.5 & 6.9 & 5.0 & 20.1 \\
\hline Higher & 5.7 & 3.9 & 0.5 & 10.0 \\
\hline \multicolumn{5}{|l|}{ Income position } \\
\hline More than sufficient & 1.0 & 5.0 & 1.1 & 4.1 \\
\hline Sufficient & 31.2 & 39.3 & 26.1 & 64.4 \\
\hline Barely sufficient & 36.6 & 37.4 & 51.7 & 24.9 \\
\hline Insufficient & 31.2 & 18.3 & 21.1 & 6.6 \\
\hline \multicolumn{5}{|l|}{ Work status } \\
\hline Employer & 46.6 & 27.5 & 36.1 & 7.5 \\
\hline Employee & 30.3 & 32.2 & 22.9 & 28.1 \\
\hline Unemployed & 5.9 & 2.7 & 4.1 & 3.2 \\
\hline Student & 8.7 & 4.1 & 4.5 & 4.9 \\
\hline Housework or inactivity & 8.5 & 33.5 & 32.4 & 56.3 \\
\hline \multicolumn{5}{|l|}{ Household connections } \\
\hline Household with only non-migrants & 62.3 & 60.4 & 33.4 & 36.3 \\
\hline Household with return migrants & 7.7 & 3.7 & 21.3 & 27.4 \\
\hline Household with current migrants & 28.9 & 33.1 & 31.8 & 27.3 \\
\hline Household with current and return migrants & 1.1 & 2.8 & 13.5 & 9.0 \\
\hline \multicolumn{5}{|l|}{ Approval of unmarried women migrating } \\
\hline Approve & 66.6 & 25.8 & 54.0 & 5.1 \\
\hline Neither approve nor disapprove & 14.9 & 22.6 & 1.6 & 1.3 \\
\hline Disapprove & 18.5 & 51.6 & 44.4 & 93.6 \\
\hline \multicolumn{5}{|l|}{ Self-efficacy (possibility of direction life) } \\
\hline Possible to determine what happens in life & 65.6 & 39.9 & 20.2 & 9.8 \\
\hline Not possible, up to fate & 34.4 & 60.1 & 79.8 & 90.2 \\
\hline \multicolumn{5}{|l|}{ Region $^{a}$} \\
\hline $1 \mathrm{MD}+\mathrm{EM}$ & 25.6 & 11.3 & 50.5 & 21.7 \\
\hline $2 \mathrm{MD}+\mathrm{RM}$ & 14.1 & 52.7 & - & 23.4 \\
\hline $3 \mathrm{LD}+\mathrm{EM}$ & 27.5 & 15.7 & - & 33.3 \\
\hline $4 \mathrm{LD}+\mathrm{RM}$ & 32.8 & 20.3 & 49.5 & 21.6 \\
\hline \multicolumn{5}{|l|}{ Expected financial gains from migration } \\
\hline No & 26.4 & 36.5 & 20.2 & 27.2 \\
\hline Yes, expected gains & 73.6 & 63.5 & 79.8 & 72.8 \\
\hline \multicolumn{5}{|l|}{ Job search costs } \\
\hline In the home country easier & 22.9 & 4.8 & 7.2 & 75.8 \\
\hline Equally easy & 17.0 & 21.5 & 24.4 & 11.0 \\
\hline In a European country easier & 60.1 & 74.0 & 68.4 & 13.2 \\
\hline Valid $\mathrm{N}=$ & 1569 & 583 & 2267 & 2940 \\
\hline
\end{tabular}


Table 5: Ordered probit analysis of emigration intentions of non-migrants (18-65 years)

\begin{tabular}{|c|c|c|c|c|c|c|c|c|}
\hline & \multicolumn{4}{|c|}{ Ghana } & \multicolumn{4}{|c|}{ Morocco } \\
\hline & \multicolumn{2}{|c|}{ Model 1} & \multicolumn{2}{|c|}{ Model 2} & \multicolumn{2}{|c|}{ Model 1} & \multicolumn{2}{|c|}{ Model 2} \\
\hline & Coef. & s.e. & Coef. & s.e. & Coef. & s.e. & Coef. & s.e. \\
\hline Age & $-0.04 * *$ & $(0.00)$ & $-0.04 * *$ & $(0.00)$ & $-0.07 * *$ & $(0.01)$ & $-0.07 * *$ & $(0.01)$ \\
\hline Sex $($ Male $=0)$ & $-0.35 * *$ & $(0.07)$ & $-0.36 * *$ & $(0.07)$ & $-1.08 * *$ & $(0.21)$ & $-1.10^{* *}$ & $(0.24)$ \\
\hline \multicolumn{9}{|l|}{ Marital status ( single $=0$ ) } \\
\hline Ever Married & 0.09 & $(0.08)$ & 0.10 & $(0.08)$ & -0.01 & $(0.19)$ & -0.01 & $(0.20)$ \\
\hline \multicolumn{9}{|l|}{ Education $($ No education $=0$ ) } \\
\hline Primary & $0.23 * *$ & $(0.10)$ & $0.25 * *$ & $(0.11)$ & $-0.41 * *$ & $(0.17)$ & $-0.45 * *$ & $(0.17)$ \\
\hline Secondary & $0.24 * *$ & $(0.12)$ & $0.25^{* *}$ & $(0.12)$ & -0.32 & $(0.30)$ & -0.33 & $(0.27)$ \\
\hline Higher & $0.33 *$ & $(0.18)$ & $0.38^{* *}$ & $(0.18)$ & -0.44 & $(0.33)$ & -0.56 & $(0.38)$ \\
\hline \multicolumn{9}{|l|}{ Income position $($ sufficient $=0$ ) } \\
\hline More than sufficient & $0.64 * *$ & $(0.31)$ & $0.67 * *$ & $(0.30)$ & $-0.99 *$ & $(0.51)$ & $-1.13 * *$ & $(0.54)$ \\
\hline Barely sufficient & 0.05 & $(0.08)$ & 0.04 & $(0.08)$ & 0.24 & $(0.16)$ & 0.26 & $(0.17)$ \\
\hline Insufficient & $0.27 * *$ & $(0.08)$ & $0.26^{* *}$ & $(0.09)$ & $0.57 * *$ & $(0.22)$ & $0.60 * *$ & $(0.23)$ \\
\hline \multicolumn{9}{|l|}{ Work status $($ Employee/worker $=0)$} \\
\hline Employer/owner business & $-0.19 * *$ & $(0.08)$ & $-0.20 * *$ & $(0.08)$ & $-0.31 *$ & $(0.16)$ & $-0.40 * *$ & $(0.17)$ \\
\hline Unemployed & -0.03 & $(0.13)$ & -0.03 & $(0.13)$ & $0.83 * *$ & $(0.39)$ & $0.87 * *$ & $(0.40)$ \\
\hline Student & -0.15 & $(0.11)$ & $-0.16^{*}$ & $(0.10)$ & 0.08 & $(0.31)$ & 0.06 & $(0.33)$ \\
\hline Housework or inactive & $-0.38 * *$ & $(0.12)$ & $-0.39 * *$ & $(0.12)$ & 0.04 & $(0.21)$ & -0.07 & $(0.23)$ \\
\hline \multicolumn{9}{|l|}{ Household connections (none $=0$ ) } \\
\hline With return migrants & -0.04 & $(0.12)$ & -0.04 & $(0.12)$ & -0.43 & $(0.31)$ & -0.36 & $(0.35)$ \\
\hline With current migrants & $0.31 * *$ & $(0.07)$ & $0.31 * *$ & $(0.07)$ & -0.19 & $(0.19)$ & -0.11 & $(0.20)$ \\
\hline With current and return migrants & 0.33 & $(0.26)$ & 0.39 & $(0.26)$ & 0.22 & $(0.26)$ & 0.15 & $(0.27)$ \\
\hline \multicolumn{9}{|l|}{ Modernity value -women migrating } \\
\hline \multicolumn{9}{|l|}{ (approve $=0$ ) } \\
\hline Approve nor disapprove & $-0.41 * *$ & $(0.10)$ & $-0.40 * *$ & $(0.09)$ & $-0.86 * *$ & $(0.17)$ & $-0.89 * *$ & $(0.18)$ \\
\hline Disapprove & $-0.38 * *$ & $(0.09)$ & $-0.40 * *$ & $(0.09)$ & $-0.68 * *$ & $(0.18)$ & $-0.73 * *$ & $(0.19)$ \\
\hline \multicolumn{9}{|c|}{ Self-efficacy (possible to determine $=0$ ) } \\
\hline Not possible, up to fate & -0.06 & $(0.07)$ & -0.06 & $(0.07)$ & -0.13 & $(0.13)$ & $-0.24 *$ & $(0.13)$ \\
\hline \multicolumn{9}{|l|}{ Region dummies $(1 \mathrm{MD}+\mathrm{EM}=0)$} \\
\hline $2 \mathrm{MD}+\mathrm{RM}$ & $0.30 * *$ & $(0.11)$ & $0.31 * *$ & $(0.11)$ & 0.17 & $(0.21)$ & 0.21 & $(0.22)$ \\
\hline $3 \mathrm{LD}+\mathrm{EM}$ & $0.25 * *$ & $(0.09)$ & $0.27 * *$ & $(0.09)$ & 0.21 & $(0.24)$ & 0.25 & $(0.26)$ \\
\hline $4 \mathrm{LD}+\mathrm{RM}$ & $0.36 * *$ & $(0.08)$ & $0.40 * *$ & $(0.09)$ & 0.06 & $(0.23)$ & 0.14 & $(0.24)$ \\
\hline \multicolumn{9}{|c|}{ Optimism gains from migration $($ no $=0$ ) } \\
\hline Yes, expected gains & - & - & $0.66^{* *}$ & $(0.09)$ & - & - & $1.12^{* *}$ & $(0.22)$ \\
\hline \multicolumn{9}{|c|}{ Optimism job search ( easier at home $=0$ ) } \\
\hline Equally easy & - & - & $-0.18^{*}$ & $(0.11)$ & - & - & -0.42 & $(0.45)$ \\
\hline Easier in Europe & - & - & -0.02 & $(0.08)$ & - & - & -0.02 & $(0.41)$ \\
\hline Threshold point 1 & -1.22 & $(0.22)$ & -1.24 & $(0.23)$ & -4.00 & $(0.54)$ & -4.41 & $(0.65)$ \\
\hline Threshold point 2 & -0.40 & $(0.22)$ & -0.38 & $(0.23)$ & -2.63 & $(0.51)$ & -2.93 & $(0.62)$ \\
\hline Threshold point 3 & 0.11 & $(0.22)$ & 0.14 & $(0.23)$ & -2.04 & $(0.49)$ & -2.31 & $(0.60)$ \\
\hline $\mathrm{N}=$ & \multicolumn{2}{|c|}{1569} & \multicolumn{2}{|c|}{1569} & \multicolumn{2}{|c|}{562} & \multicolumn{2}{|c|}{562} \\
\hline Wald $\chi^{2}(\mathrm{df})$ & \multicolumn{2}{|c|}{299.5} & & & & & & \\
\hline Log-likelihood & -16 & & -16 & & & & & \\
\hline Pseudo $\mathrm{R}^{2}$ & & & & & & & & \\
\hline
\end{tabular}

Notes: standard errors are in parentheses, the symbols * denote $\mathrm{P}<0.10, * * \mathrm{P}<0.05$. Estimation results are unweighted. 
Table 5 (continued): ordered probit analysis of emigration intentions of non-migrants (18-65 years)

\begin{tabular}{|c|c|c|c|c|c|c|c|c|}
\hline & \multicolumn{4}{|c|}{ Senegal } & \multicolumn{4}{|c|}{ Egypt } \\
\hline & \multicolumn{2}{|c|}{ Model 1} & \multicolumn{2}{|c|}{ Model 2} & \multicolumn{2}{|c|}{ Model 1} & \multicolumn{2}{|c|}{ Model 2} \\
\hline & Coef. & s.e. & Coef. & s.e. & Coef. & s.e. & Coef. & s.e. \\
\hline Age & $-0.03 * *$ & $(0.00)$ & $-0.04 * *$ & $(0.00)$ & $-0.04 * *$ & $(0.00)$ & $-0.05 * *$ & $(0.00)$ \\
\hline Sex $($ Male $=0)$ & $-0.85^{* *}$ & $(0.08)$ & $-0.95 * *$ & $(0.08)$ & $-1.03 * *$ & $(0.10)$ & $-1.03 * *$ & $(0.10)$ \\
\hline \multicolumn{9}{|l|}{ Marital status $($ single $=0$ ) } \\
\hline Ever Married & $-0.32 * *$ & $(0.08)$ & $-0.31 * *$ & $(0.08)$ & -0.09 & $(0.09)$ & -0.14 & $(0.09)$ \\
\hline \multicolumn{9}{|l|}{ Education $($ No education $=0$ ) } \\
\hline Primary & $0.18 * *$ & $(0.09)$ & $0.20 * *$ & $(0.09)$ & $0.19 *$ & $(0.12)$ & 0.17 & $(0.12)$ \\
\hline Secondary & 0.02 & $(0.13)$ & 0.01 & $(0.14)$ & $0.45^{* *}$ & $(0.10)$ & $0.45^{* *}$ & $(0.11)$ \\
\hline Higher & $-0.81 * *$ & $(0.41)$ & $-0.97 * *$ & $(0.44)$ & $0.65 * *$ & $(0.12)$ & $0.67 * *$ & $(0.13)$ \\
\hline \multicolumn{9}{|l|}{ Income position $($ sufficient $=0$ ) } \\
\hline More than sufficient & 0.06 & $(0.32)$ & 0.05 & $(0.36)$ & -0.08 & $(0.17)$ & -0.07 & $(0.15)$ \\
\hline Barely sufficient & -0.07 & $(0.09)$ & -0.11 & $(0.09)$ & 0.01 & $(0.09)$ & 0.02 & $(0.09)$ \\
\hline Insufficient & -0.06 & $(0.11)$ & -0.07 & $(0.11)$ & $0.33 * *$ & $(0.16)$ & $0.32 *$ & $(0.16)$ \\
\hline \multicolumn{9}{|l|}{ Work status $($ Employee $=0)$} \\
\hline Employer/owner business & 0.01 & $(0.08)$ & 0.04 & $(0.08)$ & $-0.29 * *$ & $(0.14)$ & $-0.31 * *$ & $(0.15)$ \\
\hline Unemployed & $0.36 * *$ & $(0.12)$ & $0.39 * *$ & $(0.11)$ & 0.05 & $(0.16)$ & 0.06 & $(0.16)$ \\
\hline Student & -0.16 & $(0.14)$ & -0.19 & $(0.14)$ & -0.13 & $(0.12)$ & -0.14 & $(0.12)$ \\
\hline Housework or inactive & 0.00 & $(0.10)$ & 0.01 & $(0.10)$ & $-0.51 * *$ & $(0.10)$ & $-0.58 * *$ & $(0.10)$ \\
\hline \multicolumn{9}{|l|}{ Household connections $($ none $=0$ ) } \\
\hline With retur $\mathrm{n}$ migrants & 0.08 & $(0.10)$ & 0.08 & $(0.10)$ & $0.28 * *$ & $(0.10)$ & $0.31 * *$ & $(0.10)$ \\
\hline With current migrants & -0.02 & $(0.08)$ & -0.02 & $(0.09)$ & $0.30 * *$ & $(0.09)$ & $0.31 * *$ & $(0.09)$ \\
\hline With current and return migrants & 0.13 & $(0.10)$ & 0.15 & $(0.11)$ & $0.40 * *$ & $(0.14)$ & $0.44 * *$ & $(0.14)$ \\
\hline \multicolumn{9}{|l|}{ Modernity value - Women migrating } \\
\hline \multicolumn{9}{|l|}{ (approve $=0$ ) } \\
\hline Approve nor disapprove & -0.20 & $(0.24)$ & -0.19 & $(0.25)$ & -0.47 & $(0.32)$ & $-0.63 * *$ & $(0.31)$ \\
\hline Disapprove & $-0.36 * *$ & $(0.07)$ & $-0.45^{* *}$ & $(0.07)$ & $-0.46^{* *}$ & $(0.12)$ & $-0.54 * *$ & $(0.13)$ \\
\hline \multicolumn{9}{|c|}{ Self-efficacy (possible to determine $=0$ ) } \\
\hline Not possible, up to fate & $-0.20 * *$ & $(0.07)$ & $-0.22 * *$ & $(0.07)$ & 0.04 & $(0.12)$ & 0.11 & $(0.13)$ \\
\hline \multicolumn{9}{|l|}{ Region dummies $(1 \mathrm{MD}+\mathrm{EM}=0)$} \\
\hline $2 \mathrm{MD}+\mathrm{RM}$ & - & - & - & - & 0.14 & $(0.12)$ & 0.16 & $(0.12)$ \\
\hline $3 \mathrm{LD}+\mathrm{EM}$ & - & - & - & - & 0.13 & $(0.12)$ & 0.19 & $(0.12)$ \\
\hline $4 \mathrm{LD}+\mathrm{RM}$ & $-0.65 * *$ & $(0.08)$ & $-0.70 * *$ & $(0.08)$ & 0.17 & $(0.12)$ & $0.23^{*}$ & $(0.13)$ \\
\hline \multicolumn{9}{|c|}{ Optimism gains from migration $(n o=0)$} \\
\hline Yes, expected gains & - & - & $1.22 * *$ & $(0.13)$ & - & - & $1.01 * *$ & $(0.14)$ \\
\hline \multicolumn{9}{|c|}{ Optimism job search ( easier at home $=0$ ) } \\
\hline Equally easy & - & - & -0.05 & $(0.13)$ & - & - & $0.31 * *$ & $(0.11)$ \\
\hline Easier in Europe & - & - & $0.49 * *$ & $(0.12)$ & - & - & $0.53 * *$ & $(0.09)$ \\
\hline Threshold point 1 & -2.82 & $(0.19)$ & -3.69 & $(0.23)$ & -2.00 & $(0.30)$ & -2.06 & $(0.35)$ \\
\hline Threshold point 2 & -1.16 & $(0.19)$ & -1.93 & $(0.21)$ & -0.86 & $(0.30)$ & -0.80 & $(0.35)$ \\
\hline Threshold point 3 & -0.69 & $(0.19)$ & -1.45 & $(0.22)$ & -0.24 & $(0.30)$ & -0.15 & $(0.35)$ \\
\hline $\mathrm{N}=$ & \multicolumn{2}{|c|}{2267} & \multicolumn{2}{|c|}{2267} & \multicolumn{2}{|c|}{2940} & \multicolumn{2}{|c|}{2940} \\
\hline Wald $\chi^{2}(\mathrm{df})$ & \multicolumn{2}{|c|}{639.9} & & & & & & \\
\hline Log-likelihood & -14 & & -14 & & & & & \\
\hline Pseudo $R^{2}$ & & & & & & & & \\
\hline
\end{tabular}

Notes: standard errors are in parentheses, the symbols $*$ denote $\mathrm{P}<0.10$, ** $\mathrm{P}<0.05$. Estimation results are unweighted. 
Table 6: Ordered probit analysis of emigration intentions of non-migrants (18-65 years): men versus women

\begin{tabular}{|c|c|c|c|c|c|c|c|c|}
\hline & \multicolumn{4}{|c|}{ Ghana } & \multicolumn{4}{|c|}{ Morocco } \\
\hline & \multicolumn{2}{|c|}{ Men } & \multicolumn{2}{|c|}{ Women } & \multicolumn{2}{|c|}{ Men } & \multicolumn{2}{|c|}{ Women } \\
\hline & Coef. & s.e. & Coef. & s.e. & Coef. & s.e. & Coef. & s.e. \\
\hline Age & $-0.04 * *$ & $(0.01)$ & $-0.04 * *$ & $(0.00)$ & $-0.08 * *$ & $(0.01)$ & $-0.06^{* *}$ & $(0.02)$ \\
\hline \multicolumn{9}{|l|}{ Marital status ( single $=0$ ) } \\
\hline Ever Married & 0.11 & $(0.13)$ & 0.10 & $(0.11)$ & 0.11 & $(0.23)$ & 0.37 & $(0.53)$ \\
\hline \multicolumn{9}{|l|}{ Education $($ No education $=0$ ) } \\
\hline Primary & 0.02 & $(0.26)$ & $0.30 * *$ & $(0.12)$ & $-0.68 * *$ & $(0.20)$ & 0.55 & $(0.48)$ \\
\hline Secondary and higher & 0.16 & $(0.26)$ & $0.34 * *$ & $(0.14)$ & -0.38 & $(0.26)$ & 0.21 & $(0.86)$ \\
\hline \multicolumn{9}{|c|}{ Income position $($ sufficient or more $=0$ ) } \\
\hline Barely sufficient & -0.16 & $(0.12)$ & 0.13 & $(0.11)$ & 0.13 & $(0.19)$ & $0.87 * *$ & $(0.29)$ \\
\hline Insufficient & 0.04 & $(0.12)$ & $0.40 * *$ & $(0.11)$ & $0.54 * *$ & $(0.23)$ & $1.77 * *$ & $(0.83)$ \\
\hline \multicolumn{9}{|l|}{ Work status $($ Employee $=0)$} \\
\hline Employer/owner business & $-0.20 *$ & $(0.12)$ & $-0.20 *$ & $(0.11)$ & $-0.48 * *$ & $(0.17)$ & $1.21 *$ & $(0.71)$ \\
\hline Unemployed & -0.00 & $(0.19)$ & -0.08 & $(0.18)$ & $0.86 * *$ & $(0.44)$ & $-{ }^{a}$ & $(-)$ \\
\hline Student & $-0.28 * *$ & $(0.13)$ & -0.01 & $(0.16)$ & 0.05 & $(0.40)$ & 1.03 & $(0.66)$ \\
\hline Housework or inactive & $-0.47 * *$ & $(0.23)$ & $-0.38 * *$ & $(0.15)$ & -0.03 & $(0.24)$ & 0.51 & $(0.52)$ \\
\hline \multicolumn{9}{|l|}{ Household connections $($ none $=0$ ) } \\
\hline With return migrants & -0.23 & $(0.18)$ & 0.05 & $(0.15)$ & 0.01 & $(0.46)$ & -0.57 & $(0.58)$ \\
\hline With current migrants & $0.24 * *$ & $(0.11)$ & $0.38 * *$ & $(0.10)$ & -0.18 & $(0.22)$ & 0.10 & $(0.49)$ \\
\hline With current and return migrants & $0.45^{*}$ & $(0.27)$ & 0.32 & $(0.45)$ & 0.02 & $(0.29)$ & 0.28 & $(0.68)$ \\
\hline \multicolumn{9}{|l|}{ Modernity value - Women migrating } \\
\hline \multicolumn{9}{|l|}{ (approve $=0$ ) } \\
\hline Neutral or disapprove & $-0.30 * *$ & $(0.10)$ & $-0.49 * *$ & $(0.10)$ & $-0.63 * *$ & $(0.19)$ & $-1.30 * *$ & $(0.33)$ \\
\hline \multicolumn{9}{|c|}{ Self-efficacy (possible to determine $=0$ ) } \\
\hline Not possible, up to fate & 0.05 & $(0.10)$ & -0.13 & $(0.09)$ & -0.18 & $(0.15)$ & -0.28 & $(0.34)$ \\
\hline \multicolumn{9}{|l|}{ Region dummies $(1 \mathrm{MD}+\mathrm{EM}=0)$} \\
\hline $2 \mathrm{MD}+\mathrm{RM}$ & $0.40 * *$ & $(0.16)$ & $0.35 * *$ & $(0.17)$ & 0.15 & $(0.22)$ & -0.20 & $(0.73)$ \\
\hline $3 \mathrm{LD}+\mathrm{EM}$ & 0.12 & $(0.13)$ & $0.42 * *$ & $(0.13)$ & 0.06 & $(0.28)$ & 1.13 & $(0.79)$ \\
\hline $4 \mathrm{LD}+\mathrm{RM}$ & $0.39 * *$ & $(0.12)$ & $0.46^{* *}$ & $(0.12)$ & 0.05 & $(0.27)$ & -0.07 & $(0.67)$ \\
\hline \multicolumn{9}{|c|}{ Optimism gains from migration $($ no $=0)$} \\
\hline Yes, expected gains & $0.64 * *$ & $(0.14)$ & $0.66 * *$ & $(0.11)$ & $1.20 * *$ & $(0.25)$ & $0.85^{* *}$ & $(0.39)$ \\
\hline \multicolumn{9}{|c|}{ Optimism job search (easier or equally } \\
\hline \multicolumn{9}{|l|}{ easy at home $=0$ ) } \\
\hline Easier in Europe & $0.17 *$ & $(0.10)$ & -0.02 & $(0.09)$ & 0.38 & $(0.26)$ & 0.16 & $(0.45)$ \\
\hline Threshold point 1 & -1.41 & $(0.38)$ & -0.48 & $(0.28)$ & -3.17 & $(0.48)$ & -0.43 & $(1.17)$ \\
\hline Threshold point 2 & -0.61 & $(0.38)$ & 0.43 & $(0.28)$ & -1.67 & $(0.46)$ & 1.07 & (1.15) \\
\hline Threshold point 3 & 0.06 & $(0.38)$ & 0.81 & $(0.28)$ & -1.01 & $(0.45)$ & 1.51 & (1.10) \\
\hline $\mathrm{N}=$ & \multicolumn{2}{|c|}{660} & \multicolumn{2}{|c|}{909} & \multicolumn{2}{|c|}{409} & \multicolumn{2}{|c|}{162} \\
\hline Wald $\chi^{2}(\mathrm{df})$ & \multicolumn{2}{|c|}{143.6} & \multicolumn{2}{|c|}{216.0} & & & & \\
\hline Log-likelihood & & & & & & & & \\
\hline Pseudo $\mathrm{R}^{2}$ & & & & & & & & \\
\hline
\end{tabular}

Notes: standard errors are in parentheses, the symbols * denote $\mathrm{P}<0.10$, ** $\mathrm{P}<0.05$. Estimation results are unweighted. (a) variable dropped due to collinearity. 
Table 6 (continued): ordered probit analysis of emigration intentions of non-migrants (18-65 years)

\begin{tabular}{|c|c|c|c|c|c|c|c|c|}
\hline & \multicolumn{4}{|c|}{ Senegal } & \multicolumn{4}{|c|}{ Egypt } \\
\hline & \multicolumn{2}{|c|}{ Men } & \multicolumn{2}{|c|}{ Women } & \multicolumn{2}{|c|}{ Men } & \multicolumn{2}{|c|}{ Women } \\
\hline & Coef. & s.e. & Coef. & s.e. & Coef. & s.e. & Coef. & s.e. \\
\hline Age & $-0.05 * *$ & $(0.01)$ & $-0.03 * *$ & $(0.00)$ & $-0.06^{* *}$ & $(0.01)$ & $-0.03 * *$ & $(0.01)$ \\
\hline \multicolumn{9}{|l|}{ Marital status $($ single $=0)$} \\
\hline Ever Married & -0.15 & $(0.12)$ & $-0.41 * *$ & $(0.12)$ & -0.13 & $(0.16)$ & 0.01 & $(0.14)$ \\
\hline \multicolumn{9}{|l|}{ Education $($ No education $=0$ ) } \\
\hline Primary & $0.25 * *$ & $(0.11)$ & 0.20 & $(0.14)$ & 0.03 & $(0.17)$ & $0.35 * *$ & $(0.17)$ \\
\hline Secondary and higher & 0.06 & $(0.15)$ & -0.20 & $(0.28)$ & $0.44^{* *}$ & $(0.14)$ & $0.59 * *$ & $(0.15)$ \\
\hline \multicolumn{9}{|c|}{ Income position $($ sufficient and more $=0$ ) } \\
\hline Barely sufficient & $-0.25 * *$ & $(0.11)$ & 0.03 & $(0.12)$ & 0.14 & $(0.13)$ & -0.13 & $(0.14)$ \\
\hline Insufficient & -0.17 & $(0.14)$ & -0.05 & $(0.15)$ & $0.71 * *$ & $(0.24)$ & -0.05 & $(0.24)$ \\
\hline \multicolumn{9}{|l|}{ Work status $($ Employee $=0)$} \\
\hline Employer/owner business & 0.13 & $(0.10)$ & -0.09 & $(0.15)$ & $-0.36 * *$ & $(0.17)$ & -0.46 & $(0.47)$ \\
\hline Unemployed & $0.37 * *$ & $(0.15)$ & $0.55^{* *}$ & $(0.19)$ & 0.38 & $(0.25)$ & -0.20 & $(0.25)$ \\
\hline Student & -0.18 & $(0.18)$ & -0.08 & $(0.23)$ & $-0.34 * *$ & $(0.14)$ & 0.07 & $(0.22)$ \\
\hline Housework or inactive & -0.19 & $(0.20)$ & 0.09 & $(0.14)$ & -0.38 & $(0.24)$ & $-0.59 * *$ & $(0.12)$ \\
\hline \multicolumn{9}{|l|}{ Household connections (none $=0$ ) } \\
\hline With return migrants & 0.08 & $(0.12)$ & 0.09 & $(0.13)$ & $0.32 * *$ & $(0.15)$ & $0.32 * *$ & $(0.15)$ \\
\hline With current migrants & 0.01 & $(0.11)$ & 0.01 & $(0.13)$ & $0.31 * *$ & $(0.12)$ & $0.39 * *$ & $(0.15)$ \\
\hline With current and return migrants & -0.08 & $(0.15)$ & $0.33^{* *}$ & $(0.14)$ & $0.47^{* *}$ & $(0.22)$ & $0.47 * *$ & $(0.20)$ \\
\hline \multicolumn{9}{|l|}{ Modernity value - Women migrating } \\
\hline \multicolumn{9}{|l|}{ (approve $=0$ ) } \\
\hline Neutral or disapprove & $-0.35 * *$ & $(0.09)$ & $-0.49 * *$ & $(0.10)$ & 0.26 & $(0.21)$ & $-0.73 * *$ & $(0.14)$ \\
\hline \multicolumn{9}{|c|}{ Self-efficacy (possible to determine $=0$ ) } \\
\hline Not possible, up to fate & $-0.21 * *$ & $(0.09)$ & -0.14 & $(0.11)$ & 0.20 & $(0.18)$ & -0.11 & $(0.16)$ \\
\hline \multicolumn{9}{|l|}{ Region dummies $(1 \mathrm{MD}+\mathrm{EM}=0)$} \\
\hline $2 \mathrm{MD}+\mathrm{RM}$ & - & - & - & - & 0.22 & $(0.17)$ & 0.09 & $(0.16)$ \\
\hline $3 \mathrm{LD}+\mathrm{EM}$ & - & - & - & - & $0.36^{* *}$ & $(0.17)$ & 0.02 & $(0.16)$ \\
\hline $4 \mathrm{LD}+\mathrm{RM}$ & $-0.49 * *$ & $(0.10)$ & $-0.92 *$ & $(0.11)$ & $0.45^{* *}$ & $(0.17)$ & -0.08 & $(0.20)$ \\
\hline \multicolumn{9}{|c|}{ Optimism gains from migration $($ no $=0$ ) } \\
\hline Yes, expected gains & $0.99 * *$ & $(0.17)$ & $1.20 * *$ & $(0.15)$ & $1.37 * *$ & $(0.18)$ & $0.60 * *$ & $(0.16)$ \\
\hline \multicolumn{9}{|c|}{ Optimism job search (easier or equally } \\
\hline \multicolumn{9}{|l|}{ easy at home $=0$ ) } \\
\hline Easier in Europe & $0.58 * *$ & $(0.10)$ & $0.44 * *$ & $(0.09)$ & $0.55^{* *}$ & $(0.11)$ & $0.41 * *$ & $(0.13)$ \\
\hline Threshold point 1 & -2.64 & $(0.23)$ & -1.08 & $(0.26)$ & -0.29 & $(0.45)$ & -0.09 & $(0.43)$ \\
\hline Threshold point 2 & -0.90 & $(0.22)$ & 0.75 & $(0.26)$ & 1.01 & $(0.45)$ & 1.27 & $(0.45)$ \\
\hline Threshold point 3 & -0.36 & $(0.23)$ & 1.12 & $(0.28)$ & 1.81 & $(0.45)$ & 1.47 & $(0.46)$ \\
\hline $\mathrm{N}=$ & \multicolumn{2}{|c|}{949} & \multicolumn{2}{|c|}{1356} & \multicolumn{2}{|c|}{798} & \multicolumn{2}{|c|}{2142} \\
\hline Wald $\chi^{2}(\mathrm{df})$ & \multicolumn{2}{|c|}{332.5} & & & & & & \\
\hline Log-likelihood & & & & & & & & \\
\hline Pseudo $R^{2}$ & & & & & & & & \\
\hline
\end{tabular}

Notes: standard errors are in parentheses, the symbols * denote $\mathrm{P}<0.10$, ** $\mathrm{P}<0.05$. Estim ation results are unweighted. 


\section{Endnotes:}

\footnotetext{
${ }^{1}$ During the process of writing this paper we discovered that we were not the only ones who used the film title 'Out of Africa' as the leading title for a paper. Kuyvenhoven (1997) and Hatton and Williamson (2003a, 2003b) used this title earlier than we did and the credit for using this title should go to them. We have stuck, however, to our title as it describes the phenomenon of emigration in Africa so well: the majority of emigrants longs for a move 'out of Africa'.

${ }^{2}$ Pioneered by Sjaastad (1962) and later on extended by economists like Bhagwati (1975), Mincer (1978), Simon (1989), Borjas (1994), Galor (1991) and Chiswick (1999).

${ }^{3}$ We use the male notation for a typical migrant in this section not just out of convenience but primarily because most of the empirical migration literature points out that men are often the ones who initiate the decision to emigrate.

${ }^{4}$ This is also related to the work by Tunali (2000) who shows for the case of Turkey that migration is viewed as a 'lottery': for a substantial portion of migrants the estimated gain of moving is negative and only a minority of movers realises very high returns.

${ }^{5}$ Testing O'Connell's theory is also not possible as we have asked respondents directly about their expectations and not their assessment of the uncertainty surrounding expectations.

${ }^{6}$ See for an extensive description of the surveys Schoorl et al. (2000).

${ }^{7}$ In Morocco, the survey was carried out in the regions of Nador in North-Eastern Morocco and in less developed southern Tiznit, both characterised by a long migration history; as well as in the more recent migration areas of Larache (North-Western Atlantic coast), Settat (near Casablanca), and less developed Khenifra in the dry and mountainous south. In Ghana, the regions studied included the developed regions of Greater Accra, and Ashanti, the latter characterised by more recent migration patterns; and the less developed regions of Eastern and Brong Ahafo. For Senegal, the choice fell on urban and relatively developed Dakar/Pikine and on the partly rural and less developed region of Diourbel/Tourba, both characterised by relatively recent migration patterns. The two regions together house about one third of the country's population. Finally, in Egypt the following large regions were selected: Cairo and Alexandria (developed, established migration), urban lower and upper Egypt (developed with recent migration patterns), and rural lower and upper Egypt, both less developed regions, the former with more established migration flows than the latter. For more details see Schoorl et al. (2000).

${ }^{8}$ In order to obtain robust variance estimates we also control for possible interaction effects in the formation of intentions within households in the sample. The estimation method therefore relaxes the assumption of the independence of observations and requires only that observations are independent across clusters, in our case: households (White, 1980). All standard errors in this paper are corrected for this clustering effect.

${ }^{9}$ We would like to thank an anonymous referee for pointing this problem out to us. However, we have also ran separate regressions with the expectations questions, used in a direct manner, and these results differ only marginally from the two-step procedure. We present the results from the latter procedure as these give a slightly better fit.

${ }^{10}$ See for a more in-depth study of the case of Morocco, Van der Erf and Heering (2002).

${ }_{11}^{11}$ Interested readers can obtain first-stage regression results upon request from the authors.

${ }^{12}$ Furthermore, we have checked for correlation between the intention to emigrate and the financial expectations tied to emigration and this correlation turns out to be quite low.

${ }^{13}$ In re-estimating the models a number of dummy variables had to be changed in order not to run into small sample problems.
} 